palabras clave

Política fiscal

Federalismo

Gobierno federal

Administración fiscal

Gobierno local

Reforma tributaria

Brasil

José Serra

Economista,

Gobernador del Estado de

São Paulo,

Ex Ministro de Estado de Salud y de Planeamiento

de la República Federativa de

Brasil

•smiyamoto@sp.gov.br

José Roberto R. Afonso

Economista del Banco Nacional

de Desarrollo Económico y Social (BNDES)

y de la Universidad Estadual

de Campinas (UNICAMP), Brasil

œ zeroberto.afonso@gmail.com
REVISTA DE LA CEPAL 91 • ABRIL 2007

\section{El federalismo}

\section{fiscal en Brasil:}

\section{una visión panorámica}

\author{
José Serra y José Roberto R. Afonso
}

$\mathrm{L}$

os estados y municipios de la federación brasileña tienen considerable autonomía en la generación directa del ingreso tributario y en la asignación de los recursos públicos, aunque esto no obedezca a un proceso planificado de descentralización fiscal. La mejora de los indicadores fiscales de los gobiernos subnacionales a partir de la Ley de Responsabilidad Fiscal contribuyó en gran medida al éxito de la política de estabilidad macroeconómica. No obstante, la Federación antepone obstáculos a la realización de una reforma del sistema tributario. Con el objeto de contribuir al debate sobre el equilibrio federativo en la división de las responsabilidades fiscales, el presente trabajo ofrece un diagnóstico del cuadro federativo y de los cambios institucionales recientes, y propone una nueva agenda federativa. 


\section{Introducción}

La federación brasileña, caracterizada por una profunda descentralización fiscal, llegó a ser acusada de impedir la estabilización de la economía, estabilización que finalmente se logró con el Plan Real, implantado en junio de 1994, sin que la estructura federativa fuera significativamente alterada.

El escaso compromiso de los gobiernos subnacionales ${ }^{1}$ brasileños con respecto de la formulación y aplicación de buenas prácticas en materia de macroeconomía (en lo que difieren poco de otras federaciones) también era tradicionalmente considerado un obstáculo para la consolidación de la estabilidad. Sin embargo, Brasil reformó profundamente las finanzas públicas a partir de fines de los años 1990, proceso que culminó con la aprobación de una ley de responsabilidad fiscal, sin precedentes en otras federaciones por el grado de transparencia y austeridad que exige a los miembros federados. La situación se invirtió a tal punto que, últimamente, los mejores resultados primarios y nominales de los estados y municipios (junto con los de las empresas estatales) han compensado el peor desempeño del gobierno central (federal) en relación con esos indicadores.

De hecho, en los últimos años la Federación dejó de ser un elemento perturbador del llamado orden económico e incluso se transformó en un factor que contribuye al éxito de la política macroeconómica de corto plazo (al menos en lo que toca a la gestión de las metas de superávit y deuda). No obstante, existe una cuestión estructural pendiente, con sus dificultades y distorsiones: la Federación es considerada por muchos el gran obstáculo para tal impulso reformador de la economía, como si la división federativa de recursos tributarios se hubiera mantenido constante desde la implantación del sistema de la Constitución de 1988. Empero, tal idea es falsa, ya que en los últimos años ocurrieron profundos cambios en las tendencias del financiamiento y del gasto público.

\section{II}

\section{Factores condicionantes}

\section{Contexto económico}

En el contexto mundial, Brasil ocupa el décimo lugar en términos de producto interno bruto, ${ }^{2}$ el quinto en términos de población (184,2 millones de habitantes) y

\footnotetext{
$\square$ Este trabajo, elaborado con los datos disponibles hasta septiembre de 2006, se basa en un artículo presentado en la Conferencia Internacional sobre Federalismo del Foro de Federaciones (Mont-Tremblant, Canadá, octubre de 1999). Refleja exclusivamente las opiniones de los autores y no la de las instituciones a las que están vinculados. El economista Rafael Barroso, Beatriz Meirelles y Kleber Castro prestaron asistencia en la elaboración del análisis y en la actualización de la base de datos estadísticos.

${ }^{1}$ En el presente trabajo el concepto de gobiernos subnacionales se utilizará para referirse al conjunto de los gobiernos, tanto estaduales, incluido el Distrito Federal, como municipales.

${ }^{2}$ En 2005, el PIB fue de 796.000 millones de dólares, en valores corrientes convertidos por el tipo de cambio corriente, según la Organización de Cooperación y Desarrollo Económicos (OCDE).
}

el quinto también en términos territoriales. Tras un largo período de estancamiento durante el siglo XIX, la economía brasileña registró el mayor crecimiento de todas las naciones del mundo entre los decenios de 1870 y de 1970; paralelamente, experimentó profundas transformaciones estructurales. No obstante, en los últimos 26 años ese ritmo de crecimiento, especialmente vigoroso tras la segunda guerra mundial, dio un fuerte giro descendente. Por eso, el ingreso por habitante (7.450 dólares) aún se ubica en el $86^{\circ}$ lugar, ${ }^{3}$ el índice de desarrollo humano $(0,792)$ en la $63^{\circ}$ posición ${ }^{4}$ y la distribución del ingreso se halla entre las más desiguales del planeta (el coeficiente de Gini fue de 0,544 en 2005).

\footnotetext{
${ }^{3}$ Según la clasificación de países del Banco Mundial para el 2002, considerado el producto nacional bruto per cápita por el método de la paridad del poder de compra.

${ }^{4}$ Informe sobre desarrollo humano (PNUD, 2005).
} 
Acostumbrado al elevado crecimiento de la producción y del empleo y a los rápidos cambios estructurales, y deseoso de promover una sustancial mejora de las condiciones sociales de vida de la población más pobre, en este comienzo de siglo Brasil ha procurado con impaciencia retomar el dinamismo de crecimiento, sin comprometer, no obstante, la estabilidad de precios duramente conquistada 12 años atrás.

No hay que olvidar que durante tres quintas partes del período de semiestancamiento económico (1980-2006) el país fue víctima de un agudo proceso de superinflación, superado solamente a mediados de los años 1990, después de por lo menos ocho intentos frustrados. A partir de entonces, se promovieron reformas tendientes a retomar el desarrollo con estabilidad y se redefinió el papel del Estado en la vida económica, ampliando el grado de apertura comercial y financiera de la economía y modificando el rumbo de las políticas sociales e industriales, además del sistema fiscal y federativo, tema sobre el que versa este trabajo.

El perfeccionamiento del federalismo fiscal en Brasil es esencial, tanto para mantener la estabilidad económica como para retomar el desarrollo sustentable, ya que la formulación e implementación de políticas económicas más apropiadas dependen, entre otras cosas, de la estructura y la armonización tributaria interna y externa. $^{5}$

\section{Marco histórico}

En un país sin grandes conflictos culturales derivados de diferencias de idioma, religión o incluso étnicas, la federación brasileña fue creada en 1891, tras la proclamación de la República, en respuesta a diferencias regionales y a necesidades administrativas en un territorio de dimensión continental. Tal federación no nació de alguna coalición "de abajo hacia arriba", sino por una decisión "de arriba", mediante el desdoblamiento de un Estado unitario. En cuanto al sistema tributario, la federación interesaba sobre todo a las provincias más desarrolladas del Sur y del Sudeste, especialmente São Paulo, donde se concentraba el nuevo sector exportador; no es casualidad que ese estado haya encabezado el movimiento republicano y el comando de la República en sus inicios. Su objetivo principal era, entre otros, lograr mayor libertad de movimiento para imponer tributos

\footnotetext{
${ }^{5}$ Véase en Oates (1999) una visión general y bastante actualizada del federalismo fiscal, tanto de sus principios teóricos como de las experiencias internacionales.
}

locales sobre el comercio exterior. ${ }^{6}$ A cambio, se ofreció a las regiones menos desarrolladas una representación más que proporcional en el Congreso Nacional.

Desde su creación, el sistema federativo brasileño ha pasado por ciclos nítidos de contracción y expansión del gobierno central. ${ }^{7}$ Así, entre 1891 y 1930, bajo la égida de la llamada República Vieja y en pleno auge de la economía primario-exportadora cafetera, el gobierno federal era relativamente débil. En ese período, su participación relativa en el gasto público nacional se redujo de cerca de tres cuartos a la mitad; al mismo tiempo, la porción del total de ingresos de los gobiernos estaduales que le correspondía a la provincia de São Paulo aumentó de poco más de un $10 \%$ a casi un $40 \%$.

A continuación se registró un ciclo de centralización, entre 1930 y 1946, cuyo punto de partida fue la Revolución de los Treinta. Dicha fase acompañó la depresión económica mundial y culminó con la dictadura de Getulio Vargas (Estado Nuevo). La centralización del poder en manos del gobierno federal permitió concluir la unificación del mercado interno y fortaleció las bases de la industrialización. En ese período, la porción que les correspondió a las autoridades federales en la división intergubernamental del gasto público aumentó de un $50 \%$ a un $55 \%$.

Al final de la segunda guerra mundial, la redemocratización del país y la nueva Constitución democrática de 1946 abrieron una nueva fase de descentralización. En la distribución del gasto público nacional, el gobierno central volvió a absorber cerca del 50\% del total en la década siguiente.

El advenimiento del régimen militar en 1964 abrió una fase de dos décadas de centralización de recursos (cuadro 1), que fue útil tanto para la reforma fiscal —en la primera mitad del período, con la concentración de los ingresos y el control de los gastos en manos del gobierno central - como para el control político y social que el régimen necesitaba. En 1983, en pleno auge de

\footnotetext{
${ }^{6}$ Una característica del sistema tributario brasileño que contrasta con la experiencia estadounidense fue destacada por el profesor Alcides Jorge Costa: el nivel intermedio de gobierno en Brasil, desde la época de la colonia, siempre logró mantener una competencia propia para gravar las exportaciones, incluso de productos industrializados. En cambio, siempre fue irrisoria la tributación sobre la propiedad, especialmente la rural, comúnmente asignada a la competencia federal. Por ejemplo, en 2005 los estados recaudaron cerca de 8.800 millones de reales por concepto de impuesto sobre la propiedad de vehículos, es decir, 36 veces más que lo que recaudó el gobierno central con el impuesto territorial rural, que ascendió a 240 millones de reales.

${ }^{7}$ Las estadísticas sobre la división de los ingresos o de los gastos por esfera de gobierno que se menciona en los próximos párrafos se basan principalmente en Goldsmith (1986).
} 
Brasil: la carga tributaria y la división federativa, 1960-2005

(Porcentajes)

\begin{tabular}{|c|c|c|c|c|c|c|c|c|c|}
\hline \multirow{2}{*}{ Año } & \multirow{2}{*}{$\begin{array}{c}\text { Carga } \\
\text { tributaria } \\
(\% \text { del PIB })\end{array}$} & \multicolumn{4}{|c|}{ Recaudación directa ${ }^{\mathrm{a}}$} & \multicolumn{4}{|c|}{ Ingreso tributario disponible ${ }^{b}$} \\
\hline & & Unión & Estados & Municipios & Total & Unión & Estados & Municipios & Total \\
\hline 1960 & 17,41 & 64,0 & 31,3 & 4,7 & 100,0 & 59,5 & 34,1 & 6,4 & 100,0 \\
\hline 1965 & 18,99 & 63,6 & 30,8 & 5,6 & 100,0 & 54,8 & 35,1 & 10,1 & 100,0 \\
\hline 1983 & 26,97 & 76,6 & 20,6 & 2,8 & 100,0 & 69,8 & 21,3 & 8,9 & 100,0 \\
\hline 1988 & 22,43 & 71,7 & 25,6 & 2,7 & 100,0 & 60,1 & 26,6 & 13,3 & 100,0 \\
\hline 1991 & 25,24 & 63,4 & 31,2 & 5,4 & 100,0 & 54,7 & 29,6 & 15,7 & 100,0 \\
\hline 2005 & 38,94 & 68,4 & 26,0 & 5,6 & 100,0 & 57,6 & 25,2 & 17,2 & 100,0 \\
\hline
\end{tabular}

Fuente: Afonso y Meirelles (2006).

a Recaudación directa = recaudación de las competencias tributarias propias directamente realizada por cada esfera de gobierno en cada estado o región.

b Ingreso tributario disponible = recaudación directa (competencias tributarias propias) más o menos transferencias constitucionales de impuestos, considerando i) las concedidas por el gobierno central, que incluyen traspasos efectivos del Fondo de Participación de los Estados (FPE), el Fondo de Participación de los Municipios (FPM), el Fondo de Compensación de Exportaciones (FPEx), el seguro-recaudación del impuesto sobre la circulación de mercaderías y servicios (ICMS) y la complementación del Fondo de Mantención y Desarrollo de la Educación Fundamental y de Valorización del Magisterio (FUNDEF), y ii) las concedidas por los estados - 25\% del impuesto sobre la circulación de mercaderías y servicios/Fondo de Compensación de Exportaciones y 50\% del impuesto sobre la propiedad de vehículos automotores (IPVA), además de la redistribución del FUNDEF-. El ingreso disponible de los municipios se compone solamente de las transferencias federales y estaduales.

la centralización, el gobierno federal registró su mayor participación en la recaudación tributaria disponible: casi un $70 \%$, proporción semejante a la que ostentaba en la división federativa del gasto público nacional.

El debilitamiento del régimen militar y los vientos de apertura política fueron moderando el poder central en la primera mitad de los años 1980, tendencia que se reafirmó en la segunda mitad de la década, con la redemocratización y la elaboración de una nueva Constitución (1987-1988). Cuando comenzó a funcionar la Asamblea Nacional Constituyente, desmintiendo la convicción dominante tanto en el Congreso como en los gobiernos (inclusive el federal) y en la prensa, el ingreso tributario disponible ya no estaba tan concentrado en las manos del gobierno central: la porción federal se había reducido a cerca del $60 \% .^{8}$

Además, en un contexto de superinflación prolongada y programas de estabilización fracasados, quedaba de manifiesto la debilidad del sistema tributario anterior, puesta de relieve por el retroceso de la carga tributaria nacional, de cerca de $25 \%$ del PIB a principios de los años 1970 a 22\% en 1988.

Desde los años 1970, las banderas de la descentralización fiscal y del debilitamiento del poder central

\footnotetext{
${ }^{8}$ Véase Serra y Afonso (1991).
}

ocupaban una posición prominente en el ideario y en la marcha de la redemocratización del país. El movimiento obtuvo gran éxito en la fase final del régimen autoritario, en la primera mitad de los ochenta. En la segunda mitad, debido a la nueva Constitución (1988) hubo otro - y fuerte- aumento de las transferencias. En efecto, la fracción de los dos principales impuestos federales - a saber, el impuesto sobre la renta (IR) y el impuesto sobre productos industrializados (IPI) - transferida a los Fondos de Participación de los Estados (FPE) y de los Municipios (FPM) aumentó del 18\% al 44\% entre 1980 y 1990. Si incluimos todas las transferencias constitucionales, la porción transferida alcanza al $47 \%$ del primer impuesto y al 57\% del segundo. En 1980 la cifra era tan solo de $20 \% .^{9}$

A partir de la promulgación de la Constitución de 1988 también se fortaleció y consolidó la capacidad de tributación propia de las esferas subnacionales de gobierno (gráfico 1). En el caso de los estados, por ejemplo, se amplió la base de incidencia del impuesto estadual

\footnotetext{
${ }^{9}$ El 3\% se destina a los bancos regionales del Norte (Banco da Amazonia, BASA), del Nordeste (BNB) y del Centro-Oeste. En este último caso, como no hay un banco regional, la cuenta está administrada por el Banco do Brasil a fondo perdido, para financiamientos regionales; el $10 \%$ del IPI se destina a un fondo estadual como compensación porque el ICMS no grava las exportaciones de productos manufacturados.
} 
GRÁFICO 1

Brasil: división federativa de la recaudación tributaria directa, 1960-2005 (Porcentajes)

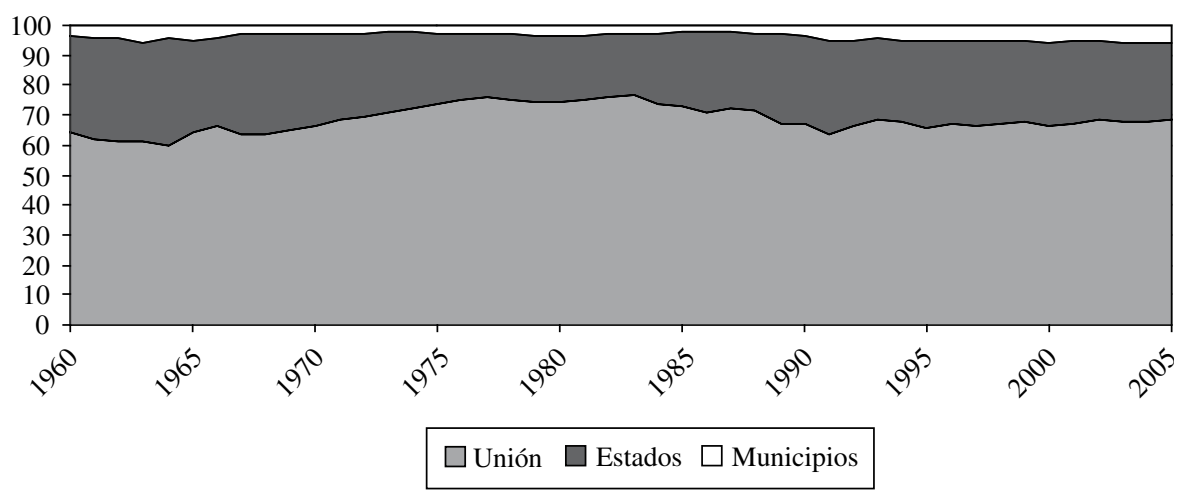

Fuente: Afonso y Meirelles (2006).

GRÁFICO 2

Brasil: división federativa del ingreso tributario disponible, 1960-2005 (Porcentajes)

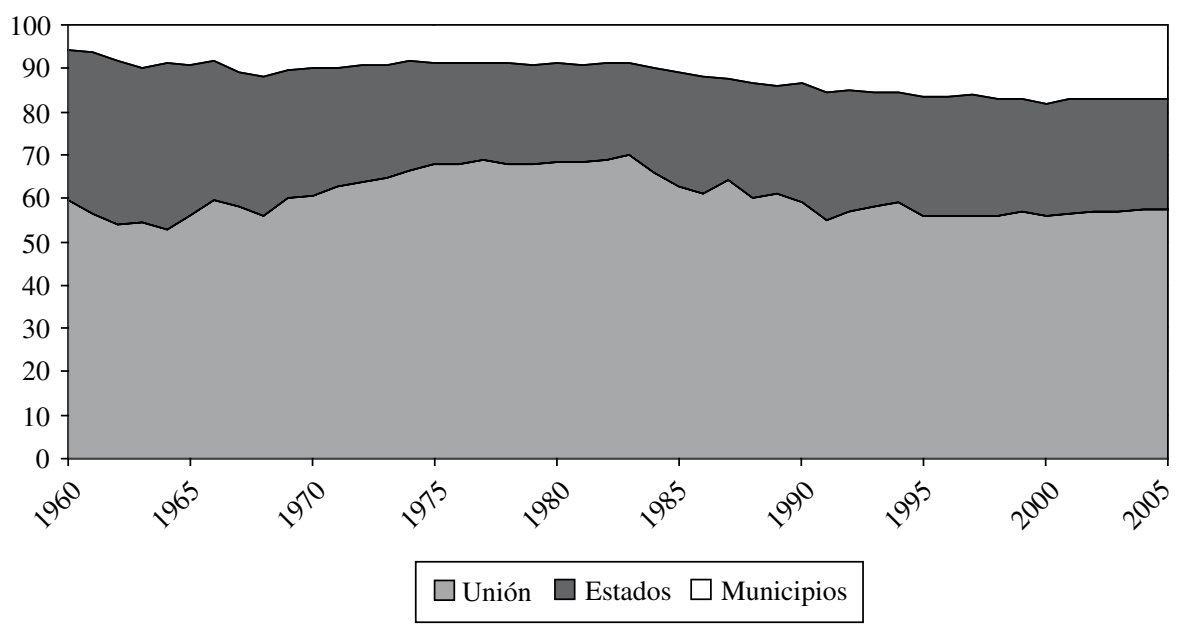

Fuente: Afonso y Meirelles (2006).

sobre la circulación de mercaderías y servicios (ICMS); el nuevo impuesto absorbió cinco impuestos federales antiguos. Además, se flexibilizaron las alícuotas y la administración correspondientes, enteramente delegadas a los propios estados. Paralelamente, aumentaron un $25 \%$ las transferencias de dicho impuesto a los municipios. La recaudación propia de los municipios también creció, duplicando con creces su proporción en el total de tributos recaudados en el país: de un $2,7 \%$ de la carga global en 1989 a un $5,6 \%$ en 2005 (gráfico 2).
Este fenómeno ocurrió junto con el aumento de la carga tributaria nacional, que fue mucho más marcado en las regiones más desarrolladas: en 2005, trepó a un índice nacional del $36,7 \%$ del PIB, ${ }^{10}$ en Rio de Janeiro y São Paulo, del $48,7 \%$ y $42,2 \%$, respectivamente; y en el Norte y Nordeste, del 22,7\% y $24 \%$ (cuadro 2).

\footnotetext{
${ }^{10}$ Las estadísticas de regionalización de los recursos tributarios presentan una consolidación nacional algo inferior al monto de la recaudación indicada por la metodología de cuentas nacionales, que incluye partidas de recaudación federal para los que no se dispone de información por estado de origen.
} 
Brasil: distribución regional de la recaudación tributaria propia, 2005

\begin{tabular}{|c|c|c|c|c|c|c|c|c|c|c|}
\hline \multirow{3}{*}{ Regiones y estados } & \multicolumn{2}{|c|}{$\begin{array}{l}\text { Recaudación } \\
\text { tributaria total }\end{array}$} & \multicolumn{8}{|c|}{ Recaudación tributaria directa $^{\mathrm{a}}$ (millones de reales) } \\
\hline & $\begin{array}{l}\text { Como } \\
\text { porcentaje } \\
\text { del PIB }\end{array}$ & $\begin{array}{l}\text { Per cápita } \\
\text { (reales por } \\
\text { habitante) }\end{array}$ & \multicolumn{2}{|c|}{ Total } & \multicolumn{2}{|c|}{ Federal } & \multicolumn{2}{|c|}{ Estadual } & \multicolumn{2}{|c|}{ Municipal $^{c}$} \\
\hline & $\mathrm{A}$ & $\mathrm{B}$ & \multicolumn{2}{|l|}{$\mathrm{C}$} & \multicolumn{2}{|l|}{$\mathrm{D}$} & \multicolumn{2}{|l|}{$\mathrm{E}$} & \multicolumn{2}{|l|}{$\mathrm{F}$} \\
\hline Brasil & 36,7 & 3857 & 710283 & 100,0 & 478499 & 100,0 & 195496 & 100,0 & 36288 & 100,0 \\
\hline Regiones más desarrolladas & 37,2 & 5047,8 & 532252,5 & 74,9 & 364985,8 & 76,3 & 136951,7 & 70,1 & 30315,0 & 83,5 \\
\hline $\begin{array}{l}\text { Región Sudeste } \\
\text { Minas Gerais } \\
\text { Espírito Santo } \\
\text { Rio de Janeiro } \\
\text { São Paulo }\end{array}$ & $\begin{array}{l}41,2 \\
28,2 \\
40,2 \\
48,7 \\
42,2\end{array}$ & $\begin{array}{l}5613,4 \\
2638,4 \\
4252,4 \\
7504,1 \\
6424,1\end{array}$ & $\begin{array}{r}440486,4 \\
50754,7 \\
14492,1 \\
115435,0 \\
259804,6\end{array}$ & $\begin{array}{r}62,0 \\
7,1 \\
2,0 \\
16,3 \\
36,6\end{array}$ & $\begin{array}{r}310118,2 \\
27179,4 \\
8027,5 \\
91888,9 \\
183022,5\end{array}$ & $\begin{array}{r}64,8 \\
5,7 \\
1,7 \\
19,2 \\
38,2\end{array}$ & $\begin{array}{r}105593,6 \\
20601,5 \\
5886,5 \\
18224,4 \\
60881,2\end{array}$ & $\begin{array}{r}54,0 \\
10,5 \\
3,0 \\
9,3 \\
31,1\end{array}$ & $\begin{array}{r}24774,6 \\
2973,8 \\
578,2 \\
5321,7 \\
15900,9\end{array}$ & $\begin{array}{r}68,3 \\
8,2 \\
1,6 \\
14,7 \\
43,8\end{array}$ \\
\hline Región Sur & 25,5 & 3402,3 & 91766,2 & 12,9 & 54867,6 & 11,5 & 31358,1 & 16,0 & 5540,5 & 15,3 \\
\hline $\begin{array}{l}\text { Paraná } \\
\text { Santa Catarina } \\
\text { Rio Grande do Sul }\end{array}$ & $\begin{array}{l}25,5 \\
26,2 \\
25,1\end{array}$ & $\begin{array}{l}3066,9 \\
3455,7 \\
3690,7\end{array}$ & $\begin{array}{l}31469,6 \\
20271,4 \\
40025,2\end{array}$ & $\begin{array}{l}4,4 \\
2,9 \\
5,6\end{array}$ & $\begin{array}{l}19415,1 \\
11758,3 \\
23694,1\end{array}$ & $\begin{array}{l}4,1 \\
2,5 \\
5,0\end{array}$ & $\begin{array}{r}10087,5 \\
7196,4 \\
14074,3\end{array}$ & $\begin{array}{l}5,2 \\
3,7 \\
7,2\end{array}$ & $\begin{array}{l}1967,0 \\
1316,7 \\
2256,8\end{array}$ & $\begin{array}{l}5,4 \\
3,6 \\
6,2\end{array}$ \\
\hline Regiones menos desarrolladas & 35,2 & 2274,3 & 179037,1 & 25,2 & 113512,9 & 23,7 & 58544,5 & 29,9 & 6979,6 & 19,2 \\
\hline $\begin{array}{l}\text { Región Norte } \\
\text { Acre } \\
\text { Amazonas } \\
\text { Pará } \\
\text { Rondônia } \\
\text { Roraima } \\
\text { Amapá } \\
\text { Tocantins }\end{array}$ & $\begin{array}{l}22,7 \\
23,3 \\
26,4 \\
18,6 \\
22,3 \\
27,0 \\
17,4 \\
28,8\end{array}$ & $\begin{array}{r}1489,4 \\
1177,0 \\
2858,5 \\
971,1 \\
1539,0 \\
1442,5 \\
1121,5 \\
1150,3\end{array}$ & $\begin{array}{r}21886,7 \\
787,4 \\
9238,8 \\
6768,3 \\
2360,9 \\
564,0 \\
666,2 \\
1501,1\end{array}$ & $\begin{array}{l}3,1 \\
0,1 \\
1,3 \\
1,0 \\
0,3 \\
0,1 \\
0,1 \\
0,2\end{array}$ & $\begin{array}{r}10250,6 \\
291,9 \\
5152,4 \\
2963,0 \\
742,4 \\
252,4 \\
289,6 \\
558,8\end{array}$ & $\begin{array}{l}2,1 \\
0,1 \\
1,1 \\
0,6 \\
0,2 \\
0,1 \\
0,1 \\
0,1\end{array}$ & $\begin{array}{r}10461,6 \\
459,0 \\
3677,3 \\
3327,4 \\
1513,4 \\
274,1 \\
341,1 \\
869,4\end{array}$ & $\begin{array}{l}5,4 \\
0,2 \\
1,9 \\
1,7 \\
0,8 \\
0,1 \\
0,2 \\
0,4\end{array}$ & $\begin{array}{r}174,5 \\
36,5 \\
409,1 \\
477,9 \\
105,1 \\
37,5 \\
35,5 \\
73,0\end{array}$ & $\begin{array}{l}3,2 \\
0,1 \\
1,1 \\
1,3 \\
0,3 \\
0,1 \\
0,1 \\
0,2\end{array}$ \\
\hline $\begin{array}{l}\text { Región Nordeste } \\
\text { Maranhãó } \\
\text { Piauí } \\
\text { Ceará } \\
\text { Rio Grande do Norte } \\
\text { Paraíba } \\
\text { Pernambuco } \\
\text { Alagoas } \\
\text { Sergipe } \\
\text { Bahia }\end{array}$ & $\begin{array}{l}24,0 \\
24,9 \\
23,1 \\
26,8 \\
23,2 \\
20,7 \\
26,2 \\
20,8 \\
25,5 \\
22,6\end{array}$ & $\begin{array}{r}1258,3 \\
709,5 \\
702,9 \\
1169,0 \\
1315,8 \\
982,2 \\
1641,2 \\
887,7 \\
1890,8 \\
1490,6\end{array}$ & $\begin{array}{r}64182,6 \\
4330,1 \\
2105,9 \\
9469,1 \\
3951,4 \\
3530,9 \\
13807,4 \\
2676,3 \\
3719,3 \\
20592,3\end{array}$ & $\begin{array}{l}9,0 \\
0,6 \\
0,3 \\
1,3 \\
0,6 \\
0,5 \\
1,9 \\
0,4 \\
0,5 \\
2,9\end{array}$ & $\begin{array}{r}30333,2 \\
2073,9 \\
844,7 \\
4592,2 \\
1571,0 \\
1488,4 \\
6392,2 \\
1080,4 \\
1213,0 \\
11077,4\end{array}$ & $\begin{array}{l}6,3 \\
0,4 \\
0,2 \\
1,0 \\
0,3 \\
0,3 \\
1,3 \\
0,2 \\
0,3 \\
2,3\end{array}$ & $\begin{array}{r}29774,1 \\
1968,8 \\
1115,7 \\
4118,8 \\
2086,7 \\
1828,9 \\
6478,1 \\
1366,3 \\
1479,9 \\
9331,0\end{array}$ & $\begin{array}{r}15,2 \\
1,0 \\
0,6 \\
2,1 \\
1,1 \\
0,9 \\
3,3 \\
0,7 \\
0,8 \\
4,8\end{array}$ & $\begin{array}{r}4075,3 \\
287,4 \\
145,5 \\
758,1 \\
293,8 \\
213,6 \\
937,1 \\
229,6 \\
1026,4 \\
183,9\end{array}$ & $\begin{array}{r}11,2 \\
0,8 \\
0,4 \\
2,1 \\
0,8 \\
0,6 \\
2,6 \\
0,6 \\
2,8 \\
0,5\end{array}$ \\
\hline $\begin{array}{l}\text { Región Centro-Oeste } \\
\text { Distrito Federal } \\
\text { Goiás } \\
\text { Mato Grosso } \\
\text { Mato Grosso do Sul }\end{array}$ & $\begin{array}{r}64,3 \\
150,8 \\
22,8 \\
24,0 \\
20,6\end{array}$ & $\begin{array}{r}7140,9 \\
30379,5 \\
1862,2 \\
2411,8 \\
2150,4\end{array}$ & $\begin{array}{r}92967,7 \\
70875,3 \\
10463,7 \\
6760,1 \\
4868,5\end{array}$ & $\begin{array}{r}13,1 \\
10,0 \\
1,5 \\
1,0 \\
0,7\end{array}$ & $\begin{array}{r}72929,2 \\
64285,3 \\
4512,6 \\
2312,2 \\
1819,0\end{array}$ & $\begin{array}{r}15,2 \\
13,4 \\
0,9 \\
0,5 \\
0,4\end{array}$ & $\begin{array}{r}18308,8 \\
5689,4 \\
5602,6 \\
3967,3 \\
3049,5\end{array}$ & $\begin{array}{l}9,4 \\
2,9 \\
2,9 \\
2,0 \\
1,6\end{array}$ & $\begin{array}{r}1729,8 \\
900,6 \\
348,6 \\
480,6\end{array}$ & $\begin{array}{l}4,8 \\
2,5 \\
1,0 \\
1,3\end{array}$ \\
\hline
\end{tabular}

Fuente: Elaboración propia, con datos de la Secretaría del Tesoro Nacional (STN, varios años), el Ministerio de Previsión y Asistencia Social, la Caja Económica Federal, el Consejo Nacional de Política Económica y el Instituto Brasileño de Geografía y Estadística (IBGE).

a Recaudación directa = recaudación de las competencias tributarias propias directamente realizada por cada esfera de gobierno en cada estado o región.

-La recaudación del gobierno central comprende impuestos (comercio exterior, patrimonio e ingreso, producción); tasas; contribuciones sociales, económicas y previsionales, y contribuciones al Fondo de Garantía de Tiempo de Servicio (FGTS). En algunos tributos, la información por estado está distorsionada porque la recaudación no está a cargo de un establecimiento o filial y la del Distrito Federal concentra recaudaciones realizadas directamente por el gobierno federal o de carácter nacional.

-La recaudación estadual comprende el impuesto estadual sobre la circulación de mercaderías y servicios (ICMS), el impuesto sobre la propiedad de vehículos automotores (IPVA), el impuesto de transmisión causa mortis y donación de cualesquiera bienes o derechos (ITCD), tasas y otros.

-La recaudación municipal comprende el impuesto de propiedad predial y territorial urbana (IPTU), el impuesto sobre servicios de cualquier naturaleza (ISS), el impuesto sobre la transmisión de bienes inmuebles intervivos (ITBI), tasas y contribución para mejoras.

-La recaudación tributaria propia municipal del Distrito Federal corresponde a la recaudación del gobierno distrital proveniente del impuesto predial y territorial urbano (IPTU), el impuesto sobre servicios de cualquier naturaleza (ISS) y el impuesto sobre la transferencia de bienes inmuebles entre vivos (ITBI).

b PIB estadual a precios corrientes estimado a partir de las proporciones del 2003.

c La recaudación municipal fue informada por la Secretaría del Tesoro Nacional sobre una muestra de 4.164 ciudades. La muestra abarca cerca del $87 \%$ de la población brasileña. 
En términos verticales, objeto principal del federalismo fiscal, casi todos los logros relativos correspondieron a la esfera municipal y poco se alteró la posición estadual, sobre todo en el concepto de ingreso tributario disponible (recaudación propia más o menos transferencias constitucionales). En términos horizontales, los recursos adicionales fueron destinados en mayor proporción a los gobiernos estaduales y municipales de las regiones menos desarrolladas, revirtiendo, en la división del ingreso tributario disponible y del gasto, la elevada concentración de la recaudación y del PIB de las regiones más desarrolladas. Ambas tendencias se mostrarán en la sección siguiente.

\section{III}

\section{Diagnóstico del cuadro federativo}

El diagnóstico actualizado de la situación de la federación brasileña ${ }^{11}$ puede resumirse en los cinco puntos siguientes.

\section{Un sistema aún en evolución}

El sistema federativo de Brasil, país cuya frontera económica continúa en expansión, todavía no está físicamente concluido, independientemente de los conflictos y las cuestiones conceptuales que subsisten. La prueba es que en los años 1970 se crearon dos estados nuevos (Mato Grosso do Sul y Rondônia) y después de laAsamblea Nacional Constituyente, otros tres (Amapá, Roraima y Tocantins); los cinco se hallan en regiones menos desarrolladas (Centro-Norte del país). Además, en la práctica, la Asamblea Nacional Constituyente puso al Distrito Federal en la misma categoría de los demás estados, al otorgarle plena representación en el Congreso Nacional y dotarlo de una Asamblea Legislativa, policía y sistema judicial propios.

Además, en virtud de la Constitución de 1988 y su ímpetu descentralizador, los municipios adquirieron estatus constitucional de cuasi miembros de la federación brasileña. En el primer momento se facilitó la creación de nuevos municipios: de poco más de 4.000 pasaron a 5.564 unidades en el 2005.12 En 1996 debió recurrirse a un cambio constitucional para frenar este impulso multiplicador, en particular al exigir que la aprobación

\footnotetext{
${ }^{11}$ Véase en Affonso (1994) un análisis más pormenorizado de la descentralización fiscal en Brasil.

${ }^{12}$ Según un estudio del Instituto de Estudios para el Desarrollo Industrial (IEDI, 2006), se estimó en cerca de 10.000 millones de reales o 0,6\% del PIB el llamado "costo político" de los municipios, esto es, el monto de gasto mínimo correspondiente al funcionamiento del ente federado municipal.
}

en el plebiscito popular abarcara ambos territorios: aquel cuya emancipación se consideraba y el de origen. ${ }^{13}$

\section{Descentralización vertical}

En relación a la carga tributaria, los estados y municipios recaudaron directamente un $31,6 \%$ del total de tributos cobrados en el país en el 2005. Una vez efectuado el reparto constitucional de los ingresos derivados de los impuestos, pasaron a disponer del $42,4 \%$ del ingreso tributario nacional, en cuya base de cálculo se incluyen las contribuciones sociales y previsionales (cuadro 1).

En cuanto al gasto, contrariamente a lo que se cree cuando se habla del sector público en Brasil, excluidos los gastos por cargas financieras y beneficios sociales, los estados y los municipios ejercen un predominio indiscutible en las acciones y servicios gubernamentales que más atienden a la población. Es importante señalar que, según las cuentas nacionales (las últimas cifras oficiales son del 2003), los gobiernos estaduales y municipales absorbieron el $71 \%$ de la nómina salarial de los funcionarios públicos en actividad en el país, el $75 \%$ de los demás gastos de financiamiento y el $85 \%$ de las inversiones fijas (cuadro 3 y gráfico 3 ). ${ }^{14}$ El gobierno central solo predomina en el caso de las

\footnotetext{
${ }^{13}$ En virtud de la enmienda constitucional $\mathrm{N}^{\circ} 15$, de diciembre de 1996, aunque ella es genérica y depende de la aprobación de una ley complementaria, se logró detener la creación de municipios: de 1997 a 2005 solo se crearon 57, que además están sujetos a la legislación anterior, toda vez que sus procesos se habían iniciado antes de la promulgación de la enmienda.

${ }^{14}$ Tal circunstancia se vio acentuada por la drástica reducción del sector de empresas estatales (no contabilizada en los cálculos de este trabajo), debido a la privatización acelerada de los años 1990, sobre todo en el ámbito federal (así ocurrió en las telecomunicaciones, la minería, la siderurgia, la petroquímica, la energía eléctrica, el transporte ferroviario y la red carretera).
} 
Brasil: división federativa del gasto público en las cuentas nacionales, 1988, 2000 y 2003

\begin{tabular}{|c|c|c|c|c|c|c|c|c|c|}
\hline \multirow{3}{*}{$\begin{array}{l}\text { Nivel de } \\
\text { gobierno }\end{array}$} & \multirow{3}{*}{ Período } & \multicolumn{8}{|c|}{ Principales gastos no financieros } \\
\hline & & \multicolumn{2}{|c|}{ Consumo intermedio ${ }^{a}$} & \multicolumn{2}{|c|}{$\begin{array}{l}\text { Remuneración de } \\
\text { empleados (activos) }\end{array}$} & \multicolumn{2}{|c|}{$\begin{array}{l}\text { Formación bruta de } \\
\text { capital fijo }\end{array}$} & \multicolumn{2}{|c|}{ Total de gastos } \\
\hline & & $\begin{array}{l}\text { Porcentaje } \\
\text { del PIB }\end{array}$ & $\begin{array}{l}\text { Porcentaje } \\
\text { total }\end{array}$ & $\begin{array}{c}\text { Porcentaje } \\
\text { del PIB }\end{array}$ & $\begin{array}{c}\text { Porcentaje } \\
\text { total }\end{array}$ & $\begin{array}{c}\text { Porcentaje } \\
\text { del PIB }\end{array}$ & $\begin{array}{l}\text { Porcentaje } \\
\text { total }\end{array}$ & $\begin{array}{c}\text { Porcentaje } \\
\text { del PIB }\end{array}$ & $\begin{array}{c}\text { Porcentaje } \\
\text { total }\end{array}$ \\
\hline \multirow{3}{*}{ Federal $^{\mathrm{c}}$} & 1988 & 2,6 & 55,3 & 3,2 & 40,5 & 1,1 & 34,4 & 6,9 & 43,7 \\
\hline & 2000 & 2,0 & 32,0 & 3,0 & 32,7 & 0,5 & 26,6 & 5,5 & 31,8 \\
\hline & 2003 & 1,7 & 25,4 & 2,9 & 29,3 & 0,3 & 15,5 & 4,9 & 26,6 \\
\hline \multirow{3}{*}{ Estadual } & 1988 & 1,2 & 25,5 & 3,3 & 41,8 & 1,2 & 37,5 & 5,7 & 36,1 \\
\hline & 2000 & 1,9 & 31,4 & 3,9 & 41,7 & 0,6 & 32,8 & 6,4 & 37,1 \\
\hline & 2003 & 2,3 & 33,3 & 4,1 & 41,4 & 0,7 & 39,2 & 7,1 & 38,2 \\
\hline \multirow{3}{*}{ Municipal } & 1988 & 0,9 & 19,1 & 1,4 & 17,7 & 0,9 & 28,1 & 3,2 & 20,3 \\
\hline & 2000 & 2,2 & 36,6 & 2,4 & 25,6 & 0,8 & 40,6 & 5,4 & 31,1 \\
\hline & 2003 & 2,8 & 41,3 & 2,9 & 29,2 & 0,8 & 45,3 & 6,5 & 35,1 \\
\hline \multirow{3}{*}{$\begin{array}{c}\text { Gobierno } \\
\text { general } \\
\text { consolidado }\end{array}$} & 1988 & 4,7 & 100,0 & 7,9 & 100,0 & 3,2 & 100,0 & 15,8 & 100,0 \\
\hline & 2000 & 6,1 & 100,0 & 9,3 & 100,0 & 1,9 & 100,0 & 17,3 & 100,0 \\
\hline & 2003 & 6,8 & 100,0 & 10,0 & 100,0 & 1,7 & 100,0 & 18,5 & 100,0 \\
\hline
\end{tabular}

Fuente: elaboración propia, sobre la base de IBGE (2003). Este es el último año en que está disponible el volumen final de las cuentas nacionales.

a El consumo intermedio comprende las compras directas de bienes y servicios para funcionamiento corriente.

b Fue descontado lo que el IBGE denomina "contribuciones sociales imputadas", que corresponden al financiamiento de la previsión de los funcionarios públicos.

c Incluye la previsión social —régimen general, administrado por el Instituto Nacional del Seguro Social (INSS) y el Fondo de Garantía de Tiempo de Servicio (FGTS)—.

GRÁFICO 3

\section{Brasil: división federativa del gasto público primario, 2003}

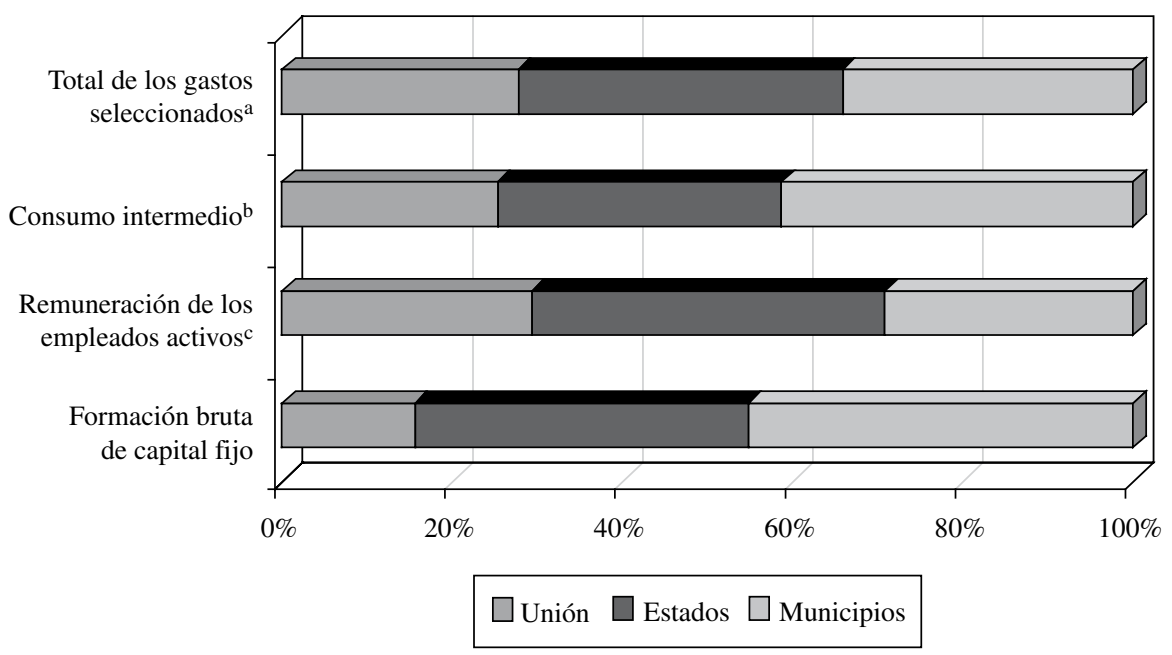

Fuente: elaboración propia, con datos del Instituto Brasileño de Geografía y Estadística (IBGE).

a Los gobiernos incluyen administraciones descentralizadas, salvo las de empresas productivas estatales. El gobierno central incluye la previsión social.

b El consumo intermedio comprende otras compras directas de bienes y servicios.

c Descontado lo que el IBGE denomina "contribuciones sociales imputadas", que corresponden al financiamiento de la previsión de los funcionarios públicos. 
Brasil: distribución regional del ingreso tributario subnacional disponible, ${ }^{\text {a }} 2005$

\begin{tabular}{|c|c|c|c|c|c|c|c|c|c|c|c|c|}
\hline \multirow{4}{*}{ Regiones y estados } & \multicolumn{4}{|c|}{ Estados } & \multicolumn{4}{|c|}{ Municipios } & \multicolumn{4}{|c|}{ Subnacional $=$ estados + municipios } \\
\hline & \multicolumn{3}{|c|}{ Ingreso disponible } & \multirow{2}{*}{$\begin{array}{l}\text { Transfer. } \\
\text { federales/ } \\
\text { ingreso } \\
\text { disponible }\end{array}$} & \multicolumn{3}{|c|}{ Ingreso disponible } & \multirow{2}{*}{$\begin{array}{c}\text { Transfer. } \\
\text { federales/ } \\
\text { ingreso } \\
\text { disponible }\end{array}$} & \multicolumn{3}{|c|}{ Ingreso disponible } & \multirow{2}{*}{$\begin{array}{l}\text { Transfer. } \\
\text { federales/ } \\
\text { rec.disp. }\end{array}$} \\
\hline & $\begin{array}{l}\text { Como \% } \\
\text { del PIB }\end{array}$ & $\begin{array}{l}\text { Reales per } \\
\text { cápita }\end{array}$ & $\begin{array}{l}\text { Millones } \\
\text { de reales y } \\
\% \text { total }^{\mathrm{c}}\end{array}$ & & $\begin{array}{l}\text { Como \% } \\
\text { del PIB }\end{array}$ & $\begin{array}{l}\text { Reales } \\
\text { per cápita }\end{array}$ & $\begin{array}{l}\text { Millones } \\
\text { de reales y } \\
\% \text { total }^{\mathrm{c}}\end{array}$ & & $\begin{array}{l}\text { Como \% } \\
\text { del PIB }\end{array}$ & $\begin{array}{l}\text { Reales per } \\
\text { cápita }\end{array}$ & $\begin{array}{l}\text { Millones } \\
\text { de reales y } \\
\% \text { total }^{\mathrm{c}}\end{array}$ & \\
\hline & $\mathrm{A}$ & B & $\mathrm{C}$ & $\mathrm{D}$ & E & $\mathrm{F}$ & G & $\mathrm{H}$ & I & $\mathrm{J}$ & $\mathrm{K}$ & $\mathrm{L}$ \\
\hline Brasil & 7,7 & 808,4 & $\begin{array}{r}114,780 \\
\mathbf{1 0 0 , 0}\end{array}$ & 22,8 & 4,3 & 456,1 & $\begin{array}{r}62,737 \\
\mathbf{1 0 0 , 0}\end{array}$ & 40,0 & 12,0 & 1264,6 & $\begin{array}{r}177,517 \\
\mathbf{1 0 0 , 0}\end{array}$ & 29,0 \\
\hline Brasil excepto São Paulo & 8,1 & 606,8 & 72,3 & 29,8 & 4,8 & 441,7 & 75,6 & 46,3 & 13,0 & 1191,1 & 73,5 & 35,9 \\
\hline Regiones más desarrolladas & 6,5 & 875,0 & 62,0 & 9,8 & 3,6 & 486,6 & 61,1 & 29,8 & 10,0 & 1361,5 & 61,6 & 17,0 \\
\hline $\begin{array}{l}\text { Región Sudeste } \\
\text { Minas Gerais } \\
\text { Espírito Santo } \\
\text { Río de Janeiro } \\
\text { São Paulo }\end{array}$ & $\begin{array}{r}6,5 \\
7,7 \\
11,1 \\
4,4 \\
6,7\end{array}$ & $\begin{array}{r}884,8 \\
723,6 \\
1170,7 \\
672,1 \\
1018,3\end{array}$ & $\begin{array}{r}46,6 \\
9,3 \\
2,7 \\
6,9 \\
27,7\end{array}$ & $\begin{array}{r}7,9 \\
15,3 \\
17,0 \\
7,8 \\
4,6\end{array}$ & $\begin{array}{l}3,5 \\
4,8 \\
6,5 \\
2,4 \\
3,3\end{array}$ & $\begin{array}{l}476,3 \\
453,2 \\
687,2 \\
376,5 \\
507,4\end{array}$ & $\begin{array}{r}44,5 \\
10,4 \\
2,8 \\
6,9 \\
24,4\end{array}$ & $\begin{array}{l}26,3 \\
43,0 \\
37,8 \\
17,7 \\
20,3\end{array}$ & $\begin{array}{r}10,0 \\
12,6 \\
17,5 \\
6,8 \\
10,0\end{array}$ & $\begin{array}{l}1361,0 \\
1176,8 \\
1857,8 \\
1048,7 \\
1525,7\end{array}$ & $\begin{array}{r}45,9 \\
9,7 \\
2,7 \\
6,9 \\
26,5\end{array}$ & $\begin{array}{r}14,3 \\
25,9 \\
24,7 \\
11,4 \\
9,8\end{array}$ \\
\hline $\begin{array}{l}\text { Región Sur } \\
\text { Paraná } \\
\text { Santa Catarina } \\
\text { Rio Grande del Sul }\end{array}$ & $\begin{array}{l}6,3 \\
6,4 \\
6,5 \\
6,2\end{array}$ & $\begin{array}{l}846,4 \\
774,1 \\
862,6 \\
906,1\end{array}$ & $\begin{array}{r}15,3 \\
5,3 \\
3,4 \\
6,6\end{array}$ & $\begin{array}{l}15,7 \\
18,3 \\
14,6 \\
14,2\end{array}$ & $\begin{array}{l}3,9 \\
4,1 \\
4,0 \\
3,6\end{array}$ & $\begin{array}{l}516,5 \\
491,4 \\
530,6 \\
532,7\end{array}$ & $\begin{array}{r}16,6 \\
6,0 \\
3,7 \\
6,9\end{array}$ & $\begin{array}{l}76,7 \\
42,5 \\
38,6 \\
36,7\end{array}$ & $\begin{array}{r}10,2 \\
10,5 \\
10,6 \\
9,8\end{array}$ & $\begin{array}{l}1363,0 \\
1265,6 \\
1393,2 \\
1438,7\end{array}$ & $\begin{array}{r}15,8 \\
5,6 \\
3,5 \\
6,7\end{array}$ & $\begin{array}{l}24,6 \\
27,7 \\
23,7 \\
22,5\end{array}$ \\
\hline Regiones menos desarrolladas & 11,1 & 719,2 & 38,0 & 44,0 & 6,4 & 415,4 & 38,9 & 55,9 & 17,6 & 1134,7 & 38,4 & 48,3 \\
\hline $\begin{array}{l}\text { Región Norte } \\
\text { Acre } \\
\text { Amazonas } \\
\text { Pará } \\
\text { Rondônia } \\
\text { Roraima } \\
\text { Amapá } \\
\text { Tocantins }\end{array}$ & $\begin{array}{r}14,1 \\
36,6 \\
8,6 \\
10,5 \\
16,2 \\
44,8 \\
30,0 \\
33,6\end{array}$ & $\begin{array}{r}927,8 \\
1847,9 \\
932,0 \\
549,5 \\
1117,8 \\
2395,1 \\
1935,7 \\
1345,2\end{array}$ & $\begin{array}{l}9,2 \\
0,8 \\
2,0 \\
2,6 \\
1,2 \\
0,6 \\
0,8 \\
1,2\end{array}$ & $\begin{array}{l}55,4 \\
80,0 \\
29,1 \\
48,9 \\
47,3 \\
79,7 \\
87,7 \\
71,4\end{array}$ & $\begin{array}{r}6,3 \\
9,1 \\
4,1 \\
6,8 \\
6,7 \\
10,3 \\
4,9 \\
14,1\end{array}$ & $\begin{array}{l}411,5 \\
460,4 \\
442,4 \\
353,0 \\
462,6 \\
550,9 \\
315,7 \\
563,4\end{array}$ & $\begin{array}{l}7,2 \\
0,4 \\
1,7 \\
2,9 \\
0,8 \\
0,3 \\
0,2 \\
0,9\end{array}$ & $\begin{array}{l}54,9 \\
69,8 \\
34,2 \\
59,6 \\
46,5 \\
70,2 \\
73,8 \\
72,1\end{array}$ & $\begin{array}{l}20,4 \\
45,7 \\
12,7 \\
17,3 \\
22,9 \\
55,2 \\
34,8 \\
47,7\end{array}$ & $\begin{array}{r}1339,3 \\
2308,3 \\
1374,4 \\
902,5 \\
1580,4 \\
2945,9 \\
2251,4 \\
1908,7\end{array}$ & $\begin{array}{l}8,5 \\
0,7 \\
1,9 \\
2,7 \\
1,0 \\
0,5 \\
0,6 \\
1,1\end{array}$ & $\begin{array}{l}55,3 \\
77,9 \\
30,8 \\
53,1 \\
47,1 \\
77,9 \\
85,7 \\
71,6\end{array}$ \\
\hline $\begin{array}{l}\text { Región Nordeste } \\
\text { Maranhão } \\
\text { Piauí } \\
\text { Ceará } \\
\text { Rio Grande do Norte } \\
\text { Paraíba } \\
\text { Pernambuco } \\
\text { Alagoas } \\
\text { Sergipe } \\
\text { Bahia }\end{array}$ & $\begin{array}{r}11,6 \\
17,6 \\
20,0 \\
11,8 \\
13,9 \\
13,6 \\
9,7 \\
15,1 \\
12,9 \\
9,0\end{array}$ & $\begin{array}{l}606,5 \\
502,2 \\
607,8 \\
516,2 \\
786,5 \\
647,9 \\
608,7 \\
644,6 \\
958,3 \\
595,6\end{array}$ & $\begin{array}{r}20,8 \\
2,1 \\
1,2 \\
2,8 \\
1,6 \\
1,6 \\
3,4 \\
1,3 \\
1,3 \\
5,5\end{array}$ & $\begin{array}{l}48,4 \\
67,1 \\
65,4 \\
48,4 \\
51,0 \\
59,1 \\
38,9 \\
59,9 \\
61,8 \\
33,9\end{array}$ & $\begin{array}{r}7,6 \\
12,8 \\
13,5 \\
8,6 \\
8,1 \\
9,0 \\
5,9 \\
9,6 \\
6,0 \\
6,3\end{array}$ & $\begin{array}{l}399,7 \\
364,4 \\
411,8 \\
374,1 \\
460,7 \\
425,6 \\
370,6 \\
411,4 \\
442,5 \\
416,6\end{array}$ & $\begin{array}{r}24,3 \\
2,6 \\
1,5 \\
3,6 \\
1,6 \\
1,8 \\
3,7 \\
1,5 \\
1,0 \\
6,9\end{array}$ & $\begin{array}{l}62,1 \\
76,4 \\
74,3 \\
62,8 \\
61,7 \\
71,3 \\
54,4 \\
69,7 \\
62,8 \\
53,8\end{array}$ & $\begin{array}{l}19,2 \\
30,4 \\
33,5 \\
20,4 \\
22,0 \\
22,6 \\
15,7 \\
24,8 \\
18,9 \\
15,4\end{array}$ & $\begin{array}{r}1006,2 \\
866,6 \\
1019,6 \\
890,4 \\
1247,2 \\
1073,6 \\
979,3 \\
1056,0 \\
1400,8 \\
1012,2\end{array}$ & $\begin{array}{r}22,0 \\
2,3 \\
1,3 \\
3,1 \\
1,6 \\
1,7 \\
3,5 \\
1,4 \\
1,2 \\
6,0\end{array}$ & $\begin{array}{l}53,8 \\
71,0 \\
69,0 \\
54,4 \\
55,0 \\
63,9 \\
44,8 \\
63,7 \\
62,1 \\
42,1\end{array}$ \\
\hline $\begin{array}{l}\text { Región Centro-Oeste } \\
\text { Distrito Federal } \\
\text { Goiás } \\
\text { Mato Grosso } \\
\text { Mato Grosso do Sul }\end{array}$ & $\begin{array}{l}8,3 \\
5,5 \\
9,8 \\
9,6 \\
9,5\end{array}$ & $\begin{array}{r}925,5 \\
1117,6 \\
800,5 \\
964,6 \\
989,3\end{array}$ & $\begin{array}{l}8,1 \\
1,8 \\
3,0 \\
1,8 \\
1,5\end{array}$ & $\begin{array}{r}19,7 \\
9,4 \\
20,6 \\
28,0 \\
19,8\end{array}$ & $\begin{array}{l}4,3 \\
1,9 \\
4,4 \\
6,7 \\
6,2\end{array}$ & $\begin{array}{l}481,6 \\
385,3 \\
359,1 \\
677,3 \\
642,4\end{array}$ & $\begin{array}{l}7,5 \\
1,1 \\
2,4 \\
2,3 \\
1,7\end{array}$ & $\begin{array}{r}36,5 \\
6,6 \\
56,2 \\
32,5 \\
33,0\end{array}$ & $\begin{array}{r}12,7 \\
7,5 \\
14,2 \\
16,3 \\
15,6\end{array}$ & $\begin{array}{l}1407,1 \\
1502,9 \\
1159,6 \\
1641,9 \\
1631,7\end{array}$ & $\begin{array}{l}7,9 \\
1,5 \\
2,8 \\
2,0 \\
1,6\end{array}$ & $\begin{array}{r}25,5 \\
8,7 \\
31,6 \\
29,9 \\
25,0\end{array}$ \\
\hline
\end{tabular}

Fuente: elaboración propia, sobre la base de Secretaría del Tesoro Nacional (sTN, varios años), Ministerio de Previsión y Asistencia Social, Caja Económica Federal, Consejo Nacional de Política Económica e Instituto Brasileño de Geografía y Estadística (IBGE).

a Ingreso tributario disponible = recaudación directa (competencias tributarias propias) más, o menos, transferencias constitucionales de impuestos (consideradas las transferencias concedidas por el gobierno central a través de traspasos efectivos del Fondo de Participación de los Estados (FPE), el Fondo de Participación de los Municipios (FPM), el Fondo de Compensación de Exportaciones (FPEx), el seguro-recaudación del impuesto sobre la circulación de mercaderías y servicios, además de la complementación del Fondo de Mantención y Desarrollo de la Educación Fundamental y de Valorización del Magisterio (FUNDEF), y las transferencias concedidas por los estados, que corresponden al $25 \%$ del impuesto sobre la circulación de mercaderías y servicios/Fondo de Compensación de Exportaciones y al 50\% del impuesto sobre la propiedad de vehículos automotores; además de la redistribución del FUNDEF). El ingreso disponible de los municipios se compone solamente de las transferencias federales y estaduales.

b PIB estadual a precios corrientes estimado a partir de las proporciones del 2003.

c Para Brasil, primera línea, columnas C, G y K, el monto está expresado en millones de reales corrientes. 
CUADRO 5

Brasil: distribución regional de la población, el ingreso y la representación política, 2005

\begin{tabular}{|c|c|c|c|c|c|c|c|c|c|}
\hline \multirow{2}{*}{ Regiones y estados } & \multicolumn{2}{|c|}{ Población } & \multicolumn{2}{|c|}{$\begin{array}{l}\text { Producto interno bruto } \\
\qquad(\mathrm{PIB})^{\mathrm{a}}\end{array}$} & \multirow{2}{*}{$\begin{array}{c}\text { PIB } \\
\text { per cápita }\end{array}$} & \multirow{2}{*}{$\begin{array}{c}\begin{array}{c}\text { Condición } \\
\text { vida }\end{array} \\
\text { Índice }=100\end{array}$} & \multicolumn{3}{|c|}{ Distribución de las bancadas } \\
\hline & $\begin{array}{l}\text { Millones de } \\
\text { habitantes }\end{array}$ & Porcentajes & $\begin{array}{l}\text { Millones de } \\
\text { reales }\end{array}$ & Porcentajes & & & $\begin{array}{l}\text { Cámara de } \\
\text { Diputados }\end{array}$ & Senado & Congreso \\
\hline \multirow[t]{2}{*}{ Brasil } & 184,2 & & 1937598 & & 10521 & 0,766 & 513 & 81 & 594 \\
\hline & & & & & & & $\%$ & $\%$ & $\%$ \\
\hline Regiones más desarrolladas & 105,4 & 57,3 & 1429341 & 73,8 & 13556 & 0,799 & 49,9 & 25,9 & 46,6 \\
\hline Región Sudeste & 78,5 & 42,6 & 1069192 & 55,2 & 13625 & 0,791 & 34,9 & 14,8 & 32,2 \\
\hline Minas Gerais & 19,2 & 10,4 & 179972 & 9,3 & 9356 & 0,773 & 10,3 & 3,7 & 9,4 \\
\hline Espírito Santo & 3,4 & 1,9 & 36083 & 1,9 & 10588 & 0,765 & 1,9 & 3,7 & 2,2 \\
\hline Rio de Janeiro & 15,4 & 8,4 & 237046 & 12,2 & 15410 & 0,807 & 9,0 & 3,7 & 8,2 \\
\hline São Paulo & 40,4 & 22,0 & 616091 & 31,8 & 15234 & 0,820 & 13,6 & 3,7 & 12,3 \\
\hline Región Sur & 27,0 & 14,6 & 360149 & 18,6 & 13353 & 0,808 & 15,0 & 11,1 & 14,5 \\
\hline Paraná & 10,3 & 5,6 & 123264 & 6,4 & 12013 & 0,787 & 5,8 & 3,7 & 5,6 \\
\hline Santa Catarina & 5,9 & 3,2 & 77462 & 4,0 & 13205 & 0,822 & 3,1 & 3,7 & 3,2 \\
\hline Rio Grande do Sul & 10,8 & 5,9 & 159422 & 8,2 & 14700 & 0,814 & 6,0 & 3,7 & 5,7 \\
\hline Regiones menos desarrolladas & 78,7 & 42,7 & 508257 & 26,2 & 6456 & 0,713 & 50,1 & 74,1 & 53,4 \\
\hline Región Norte & 14,7 & 8,0 & 96415 & 5,0 & 6561 & 0,725 & 12,7 & 25,9 & 14,5 \\
\hline Acre & 0,7 & 0,4 & 3382 & 0,2 & 5055 & 0,697 & 1,6 & 3,7 & 1,9 \\
\hline Amazonas & 3,2 & 1,8 & 34941 & 1,8 & 10811 & 0,713 & 1,6 & 3,7 & 1,9 \\
\hline Pará & 7,0 & 3,8 & 36375 & 1,9 & 5219 & 0,723 & 3,3 & 3,7 & 3,4 \\
\hline Rondônia & 1,5 & 0,8 & 10573 & 0,5 & 6893 & 0,735 & 1,6 & 3,7 & 1,9 \\
\hline Roraima & 0,4 & 0,2 & 2088 & 0,1 & 5340 & 0,746 & 1,6 & 3,7 & 1,9 \\
\hline Amapá & 0,6 & 0,3 & 3839 & 0,2 & 6462 & 0,753 & 1,6 & 3,7 & 1,9 \\
\hline Tocantins & 1,3 & 0,7 & 5217 & 0,3 & 3998 & 0,710 & 1,6 & 3,7 & 1,9 \\
\hline Región Nordeste & 51,0 & 27,7 & 267195 & 13,8 & 5238 & 0,676 & 29,4 & 33,3 & 30,0 \\
\hline Maranhão & 6,1 & 3,3 & 17411 & 0,9 & 2853 & 0,636 & 3,5 & 3,7 & 3,5 \\
\hline Piauí & 3,0 & 1,6 & 9120 & 0,5 & 3044 & 0,656 & 1,9 & 3,7 & 2,2 \\
\hline Ceará & 8,1 & 4,4 & 35392 & 1,8 & 4369 & 0,700 & 4,3 & 3,7 & 4,2 \\
\hline Rio Grande do Norte & 3,0 & 1,6 & 17053 & 0,9 & 5679 & 0,705 & 1,6 & 3,7 & 1,9 \\
\hline Paraíba & 3,6 & 2,0 & 17072 & 0,9 & 4749 & 0,661 & 2,3 & 3,7 & 2,5 \\
\hline Pernambuco & 8,4 & 4,6 & 52619 & 2,7 & 6254 & 0,705 & 4,9 & 3,7 & 4,7 \\
\hline Alagoas & 3,0 & 1,6 & 12857 & 0,7 & 4264 & 0,649 & 1,8 & 3,7 & 2,0 \\
\hline Sergipe & 2,0 & 1,1 & 14573 & 0,8 & 7409 & 0,682 & 1,6 & 3,7 & 1,9 \\
\hline Bahia & 13,8 & 7,5 & 91099 & 4,7 & 6594 & 0,688 & 7,6 & 3,7 & 7,1 \\
\hline Región Centro-Oeste & 13,0 & 7,1 & 144647 & 7,5 & 11110 & 0,737 & 8,0 & 14,8 & 8,9 \\
\hline Distrito Federal & 2,3 & 1,3 & 47006 & 2,4 & 20148 & 0,844 & 1,6 & 3,7 & 1,9 \\
\hline Goiás & 5,6 & 3,1 & 45863 & 2,4 & 8162 & 0,776 & 3,3 & 3,7 & 3,4 \\
\hline Mato Grosso & 2,8 & 1,5 & 28158 & 1,5 & 10046 & 0,773 & 1,6 & 3,7 & 1,9 \\
\hline Mato Grosso do Sul & 2,3 & 1,2 & 23619 & 1,2 & 10433 & 0,778 & 1,6 & 3,7 & 1,9 \\
\hline
\end{tabular}

Fuente: elaboración propia, con datos del Instituto Brasileño de Geografía y Estadística (IBGE), sobre población y PIB; del Programa de las Naciones Unidas para el Desarrollo (PNUD), sobre el índice de desarrollo humano para el 2000; y del Congreso, sobre el número de parlamentarios.

a PIB estadual a precios corrientes, estimado a partir de las proporciones del 2003. 
transferencias a personas, básicamente beneficios previsionales y pagos de intereses de la deuda pública, en las que abarcó cerca del $85 \%$ del gasto consolidado de todos los gobiernos.

La evolución del gasto primario gubernamental en el período posterior a la Asamblea Nacional Constituyente no deja dudas respecto de la descentralización, ya que refleja la redistribución de los ingresos tributarios, aunque tal proceso se haya desarrollado sin la adecuada planificación o coordinación. En efecto, en 1988 el gobierno central absorbía el $44 \%$ de la demanda gubernamental de bienes y servicios (incluido el factor trabajo); en el 2003, esa proporción se había reducido al 27\% (cuadro 3). En los últimos años, la división del gasto global acusa la reacción del gobierno central al rápido aumento de los gastos por concepto de transferencia de ingreso, especialmente los beneficios sociales (previsionales y de la asistencia social) y los intereses de la deuda pública.

Los indicadores de la descentralización fiscal, medidos por los índices de participación de los gobiernos subnacionales en el ingreso y en el gasto total, además de la gran autonomía en el cobro de sus tributos y en la elaboración de sus presupuestos, sitúan a Brasil en una posición cercana a las federaciones más desarrolladas. Entre los países en desarrollo es, sin duda, el que más ha avanzado en términos de autonomía. ${ }^{15}$

A ese respecto, cabe recordar que Shah (1994) elaboró un índice de autonomía de los gobiernos subnacionales, teniendo en cuenta la proporción de los gastos financiados con recursos propios o recibidos de terceros, pero sin vínculos específicos. En un grupo de 10 países, entre ricos y pobres, el mayor índice es el de Brasil, que supera incluso a aquellos de los Estados Unidos, Alemania y Canadá.

\section{Desconcentración horizontal}

Simultáneamente con la descentralización vertical en la división de los recursos públicos, se registró una profunda desconcentración horizontal del ingreso.

La concentración de la recaudación tributaria federal en las regiones más desarrolladas tiene como contrapartida un esquema de reparto de impuestos federales

\footnotetext{
${ }^{15}$ El índice de participación de los gobiernos subnacionales en la recaudación tributaria directa no tiene precedente en economías de tamaño semejante. Se parece a los indicadores de las federaciones más desarrolladas del mundo, como Canadá, Australia, Estados Unidos y Alemania, y supera a los de estados unitarios con estrategias de descentralización administrativa como Francia e Inglaterra.
}

que favorece proporcionalmente más a los gobiernos subnacionales de las regiones menos desarrolladas (véase en el cuadro 4 la posición actualizada al 2005), esto sin contar la mayor participación de esas regiones en la división de gastos federales directos en medidas sociales básicas.

Por lo que respecta a la desconcentración regional del ingreso tributario, el examen del caso de São Paulo es ilustrativo. Se trata de la unidad más populosa y desarrollada de la federación, donde vive el $22 \%$ de la población del país y se genera más del $31 \%$ de la producción nacional, lo que significa un ingreso per cápita $45 \%$ superior al promedio nacional (cuadro 5). En este estado se recaudó cerca del $37 \%$ de los tributos reunidos en todo el país en 2005. La proporción más baja fue la de los tributos estaduales ( $31 \%$ ), lo que refleja la adopción parcial del principio de destino en la incidencia del impuesto sobre la circulación de mercaderías y servicios (ICMS) en las operaciones interestaduales; las más altas (38\% y $44 \%)$ correspondieron a los tributos federales y municipales, respectivamente.

En consecuencia, la carga tributaria paulista equivalió al $42 \%$ del PIB estadual, mientras la carga media nacional fue del 36,7\% del PIB. Esta diferencia también aparece en la medición de la recaudación per cápita, ya que el promedio recaudado en São Paulo fue de casi 6.500 reales, mientras el promedio del país era de 3.900 reales (véase nuevamente el cuadro 2 ).

Cuando pasamos del análisis de la recaudación tributaria directa al del ingreso efectivamente disponible - es decir, una vez computado el reparto constitucional de impuestos entre gobiernos- constatamos que en el 2005 São Paulo obtenía el 26,5\% del ingreso disponible de todos los gobiernos estaduales y municipales del país (cuadro 4), o sea, casi cinco puntos porcentuales menos que la participación relativa del estado paulista en la generación del PIB nacional. Esta diferencia revela la exacta dimensión del grado de desconcentración regional promovida por el sistema tributario. ${ }^{16}$

La importancia relativa del ingreso estadual y municipal expresada como proporción del ingreso de cada estado también evidencia el avance de esa desconcentración regional. En el 2005, el ingreso disponible de los gobiernos subnacionales en São Paulo equivalía a solo el $10 \%$ del PIB del estado; en el promedio de las

\footnotetext{
16 Tal diferencia disminuirá un poco una vez computada la recaudación directa de otros tributos estaduales y de los tributos municipales, cuya carga en São Paulo debe superar la del resto del país.
} 


\section{Brasil: distribución regional de la población, producto interno bruto} e ingreso tributario subnacional, 2005a

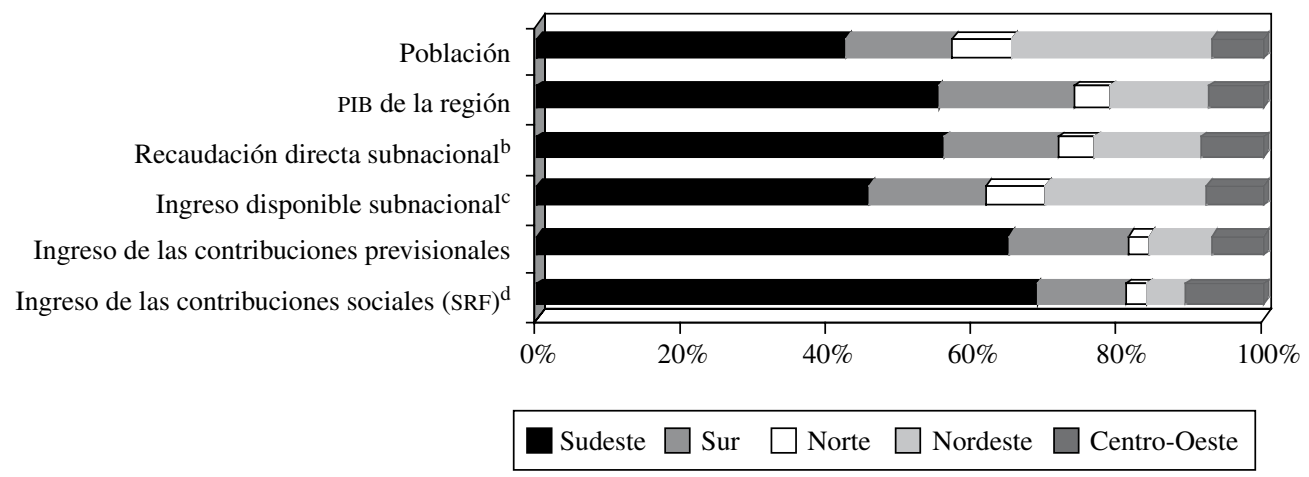

Fuente: elaboración propia, con datos del Instituto Brasileño de Geografía y Estadística (IBGE), sobre población y PIB a precios básicos; de la Secretaría del Tesoro Nacional, la Secretaría Federal de Impuestos Internos (SRF), el Ministerio de Previsión y Asistencia Social y el Consejo Nacional de Política Económica, sobre recursos tributarios. Los datos sobre la población, el PIB y la recaudación directa son del 2005; sobre lo demás, del 2004.

a Recursos tributarios: agregados los de los estados y municipios de cada región.

b La recaudación directa comprende los tributos de competencia propia.

c En el ingreso disponible se consideran, además, las transferencias de impuestos concedidas por la Unión.

d $\mathrm{SRF}=$ datos de la Secretaria da Receita Federal (la secretaría federal de impuestos internos).

tres regiones menos desarrolladas, equivalía al $18 \%$ del producto regional (cuadro 4).

El mismo análisis puede extrapolarse del caso aislado de São Paulo a la distribución entre las macrorregiones geográficas, en la cual la comparación entre la división de la población y de la economía, por una parte, y de los ingresos tributarios, por otra, refuerza el carácter descentralizador del sistema brasileño (gráfico 4). ${ }^{17}$

Los gobiernos subnacionales de las tres macrorregiones menos desarrolladas tienen el 38\% del total del ingreso tributario disponible (recaudación propia con más, o menos, transferencias obligatorias de impuestos) de esas esferas de gobierno, proporción superior en 12 puntos porcentuales a su participación en el PIB nacional, que es del 26\%. En el caso del Sudeste tales porcentajes son, respectivamente, de $46 \%$ y $55 \%$.

Para visualizar mejor la descentralización se puede comparar el ingreso efectivamente disponible de los gobiernos de cada unidad federada con el PIB respectivo (véanse las regiones en el gráfico 5 y el desglose estadual más atrás, en el cuadro 4). El índice nacional en 2005 era del 12\%; en las dos regiones más desarrolladas esa proporción equivalía a solo 10 puntos porcentuales del $\mathrm{PIB}$, mientras que en el Centro-Oeste sube a aproxima-

17 Véase el desglose en el cuadro 2, el cuadro 4 y más adelante en el cuadro 5 . damente $13 \%$ y en el Nordeste y Norte llega al $20 \%$. La dispersión por estado es aún más acentuada y supera el 30\% del PIB en algunos estados del Nordeste y del Norte. En el caso extremo, Roraima dispone de un ingreso tributario equivalente al 55\% del PIB local (véase otra vez el cuadro 4).

La acentuada redistribución regional del ingreso tributario disponible se debe a las transferencias federales de impuestos a los estados y municipios. Por ejemplo, en el 2005 se traspasaron cerca de 740 reales por habitante a los gobiernos de la región Norte; por otra parte, los gobiernos de la región Sudeste recibieron solo 195 reales por habitante (gráfico 6). En esta última región y en el Sur, de cada real recaudado a través de impuestos sobre la renta o sobre productos industrializados, volvieron 14 centavos mediante los fondos de participación (FPM y FPE). ${ }^{18}$

En el caso específico del estado de São Paulo, de cada real recaudado de impuesto sobre la renta e impuesto sobre productos industrializados, solo seis centavos

\footnotetext{
${ }^{18}$ Cabe recordar que, en el Fondo de Participación de los Estados (FPE), el índice de participación del Sur-Sudeste se limitó al 15\%, en virtud de la ley (aprobada en 1989) por la que se adoptó una tabla fija de prorrateo en lugar de la fórmula que ponderaba la inversión del ingreso per cápita. La actualización de ese parámetro amenazaba con disminuir el peso relativo de las regiones menos desarrolladas que, al crecer proporcionalmente más en las décadas de 1970 y 1980, habían acortado la distancia que las separaba de las regiones de mayor ingreso.
} 
GRÁFICO 5

Brasil: ingreso tributario disponible subnacional, ${ }^{a}$ por región, 2005

(Como proporción del producto interno bruto)

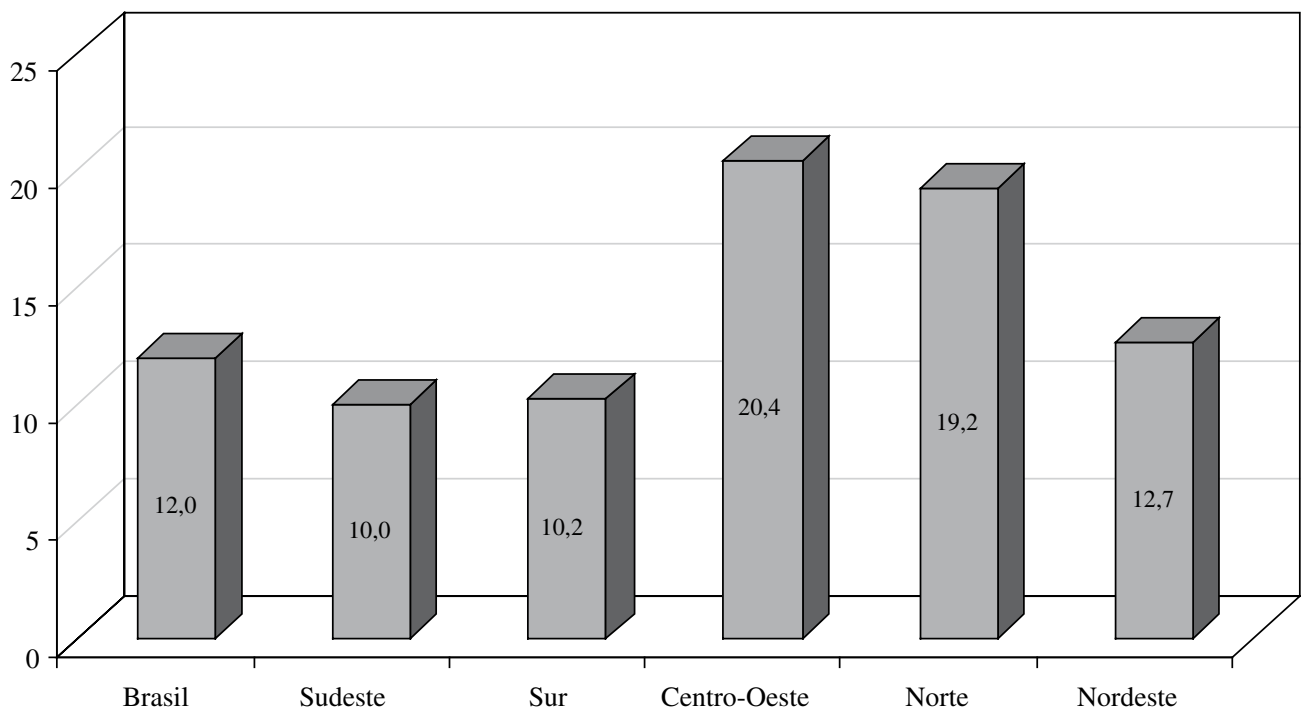

Fuente: elaboración propia, con datos de la Secretaría del Tesoro Nacional, el Consejo Nacional de Política Económica (recursos tributarios) y el Instituto Brasileño de Geografía y Estadística (IBGE) (producto interno bruto a precios básicos).

a El ingreso tributario disponible comprende la recaudación propia de los estados de cada región más las respectivas transferencias de impuestos federales y estaduales.

GRÁFICO 6

Brasil: transferencias de impuestos federales per cápita a las regiones, ${ }^{a} 2005$ (En reales)

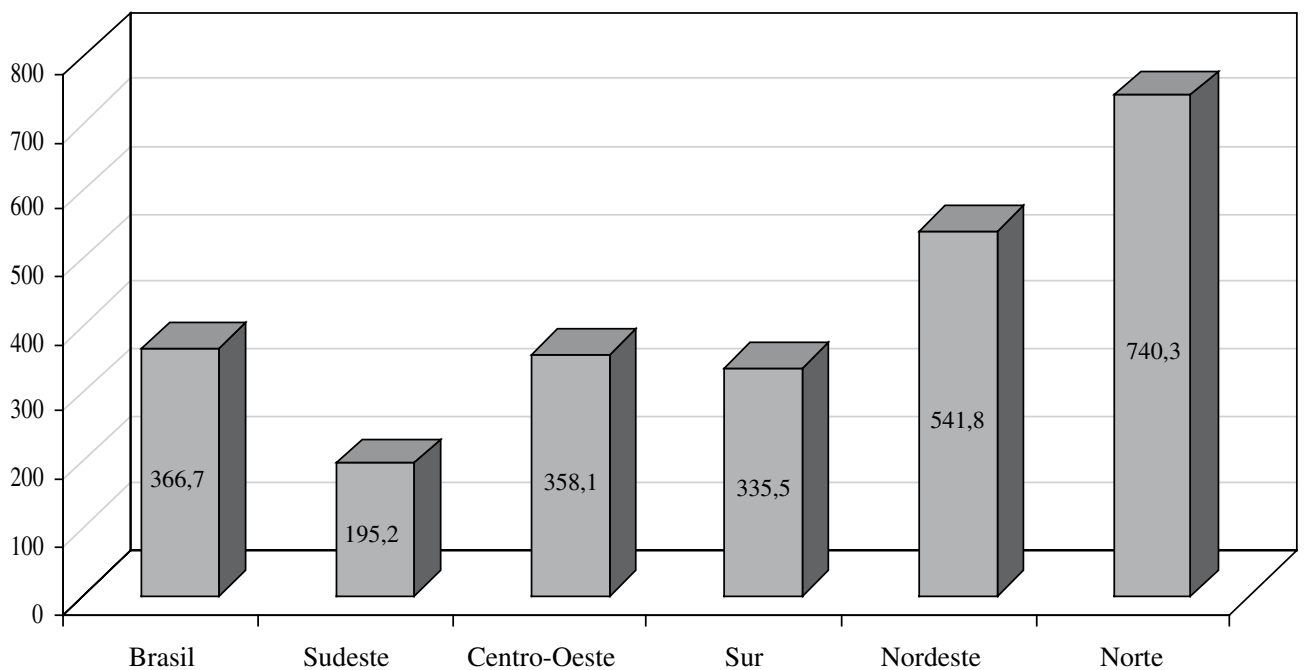

Fuente: elaboración propia, con datos de la Secretaría del Tesoro Nacional y del Instituto Brasileño de Geografía y Estadística (IBGE).

a Comprende las transferencias constitucionales de impuestos concedidas por el gobierno central a los estados y municipios de cada región. 
vuelven al estado a través de los FPM y FPE. En números absolutos, São Paulo recaudó 53.200 millones de reales de impuestos sobre la renta y 12.300 millones provenientes del impuesto sobre productos industrializados en 2005. En ese mismo año recibió 3.600 millones de reales del FPM y solamente 255 millones del FPE.

Por último, cabe mencionar la evolución de los ingresos tributarios disponibles en los gobiernos subnacionales en el período posterior a la Asamblea Nacional Constituyente. Los datos disponibles confirman el comportamiento más favorable en las regiones menos desarrolladas. Considerando solo el ingreso proveniente de los principales tributos y de las transferencias federales (sobre la misma base presentada más atrás en el cuadro 4) es posible comparar las tasas de crecimiento real en el período 1988 a 2005: los recursos disponibles de los gobiernos subnacionales aumentaron un 4,3\% al año; la región Sur se mantuvo dentro de la tasa nacional; por encima de esta, el crecimiento anual del Nordeste fue del 5\%, el del Centro-Oeste del 6\% y el del Norte del 7,6\%; el del Sudeste, en cambio, fue de 3,3\%. El estado más rico (São Paulo) de los 27 del país fue el que registró la menor expansión media, de solo un 2,7\% al año; en el otro extremo, Maranhão y Piauí registraron un aumento de recursos de aproximadamente un $6 \%$ al año.

\section{Atribuciones gubernamentales}

Si bien el capítulo de la Constitución federal que trata sobre el sistema tributario y las leyes complementarias que lo regulan es bastante preciso y detallado en cuanto a las competencias y la distribución de los ingresos tributarios de cada uno de los tres niveles de gobierno, el capítulo constitucional correspondiente a las atribuciones gubernamentales es mucho más vago y no establece una clara distribución de tareas entre esas esferas.

Se observa una superposición de medidas en algunas áreas (como medio ambiente) y una escasez en otras (como seguridad). El gobierno central no ha logrado ejercer satisfactoriamente su función de coordinación y los gobiernos subnacionales adoptan políticas autónomas. Si bien por una parte el gobierno central o incluso algunos estados reducen su participación en las inversiones y programas de duración continuada, por otra no transfieren personal ni bienes a las unidades estaduales o locales, lo que, entre otras cosas, genera un aumento imprevisto de los gastos públicos agregados.

Otro factor constitucional que contribuyó a tornar más rígidas las relaciones fiscales dentro de la federación fueron los dispositivos que impusieron el régimen único de trabajo para los funcionarios de las tres esferas de gobierno, la garantía de jubilaciones precoces e integrales en el área pública y la transformación en estatutarios de todos los funcionarios regidos por las leyes del trabajo del sector privado (Consolidación de las Leyes de Trabajo), de acuerdo con la propuesta y el esfuerzo del entonces llamado Centrão, agrupación que reunió a parlamentarios más conservadores durante la Asamblea Constituyente de 1987-1988; la propuesta, naturalmente, contó con el apoyo de los partidos de izquierda (ligados a las asociaciones de funcionarios).

De todos modos, la estructura de financiamiento y de gasto del gobierno federal mantuvo su carácter redistributivo de los recursos entre regiones. Así se desprende de la comparación entre la distribución regional de las fuentes y los usos de los recursos del gobierno federal, especialmente aquellos vinculados a medidas sociales básicas. También en la ejecución directa del gasto federal se comprueba una acentuada redistribución regional de recursos: basta comparar los datos sobre la composición regional de la recaudación de las contribuciones sociales y la de los principales programas sociales cubiertos por tales fuentes. Así, por ejemplo, en el Sudeste se recaudaron cerca de dos tercios de las contribuciones, pero esta región recibe porcentajes bastante inferiores del total del gasto del gobierno central en algunas medidas sociales básicas: $21 \%$ de la previsión rural y $34 \%$ de los beneficios continuados tanto de la asistencia social como de los programas de atención primaria de la salud. En el Nordeste, que abarca apenas el 6\% de la recaudación nacional de contribuciones sociales, la participación en los programas antes mencionados llega al $37 \%$ en la previsión, $47 \%$ en la asistencia social y $36 \%$ en la salud.

Ese patrón se reproduce en el conjunto de la previsión social (el régimen de los trabajadores del sector privado), donde la recaudación de las contribuciones sobre la nómina salarial se concentra en los estados más desarrollados y la distribución de los beneficios previsionales está regionalmente mucho más desconcentrada. ${ }^{19}$ En 2004, el Nordeste, por ejemplo, absorbía respectivamente el $8,3 \%$ y el $20,2 \%$ de los ingresos y gastos, mientras que las cifras para el estado de São Paulo eran de $43,2 \%$ y $30,7 \%$. En el cómputo general, el papel fuertemente redistributivo del régimen actual de previsión social queda a la vista por el beneficio medio pagado como

\footnotetext{
${ }^{19}$ Fuente principal de estos datos son el Anuario Estadístico de la Previsión Social y el Boletín Estadístico de la Previsión Social, ambos del Ministerio de Previsión y Asistencia Social (MPAS).
} 
proporción del PIB per cápita. Actualmente tal proporción equivale a cerca del $49 \%$ en la región Sudeste y salta al $80 \%$ en el Nordeste. En algunos estados el beneficio medio es mayor que el respectivo ingreso per cápita. En los estados de Maranhão y Piauí esa relación es igual a $132 \%$ y $122 \%$, respectivamente.

\section{Redistribución en la representación parlamentaria}

Desde el punto de vista político el sistema federativo brasileño también promueve una considerable redistribución de poder en la representación parlamentaria.

El Senado Federal, creado según el modelo estadounidense, está constituido por representación igualitaria de tres senadores por estado. Un conjunto de estados que reúne el $43 \%$ de la población brasileña (regiones Norte, Nordeste y Centro-Oeste) tiene el 74\% de los escaños (cuadro 5). El Senado brasileño examina y vota todos los proyectos de ley y enmiendas constitucionales que pasan por la Cámara de Diputados y tiene poder de veto; además, ostenta atribuciones exclusivas, como la aprobación de embajadores y dirigentes de varios organismos gubernamentales y la fijación (y excepción) de márgenes de endeudamiento para estados y municipios. Asimismo, el Senado, llamado cámara alta, solo posee menos poder que la cámara baja en un aspecto: los proyectos de ley del gobierno ingresan al Congreso por la Cámara de Diputados, que tiene la palabra final cuando, eventualmente, el Senado los devuelve modificados. Por otra parte, en la Cámara de Diputados la representación no es proporcional a la población de los estados; hay un máximo de 70 parlamentarios por estado y un mínimo de ocho. La sobrerrepresentación se concentra en estados poco populosos de la región Norte y la subrepresentación en la región Sudeste. En los casos extremos, la elección de un diputado en el estado más populoso requiere 16 veces más votos que la elección de un diputado en el estado menos populoso del país.

Para Stepan (1997) estos desequilibrios de representación son parte importante de los sistemas federales que restringen la democracia (demo-constraining federal systems), de los cuales Brasil es el caso más significativo. Se remontan a la fundación de la República, pero aumentaron en el período posterior a la segunda guerra mundial y más aún después de la creación de seis nuevos estados y de la transformación del Distrito Federal en estado, para todo efecto práctico.

\section{IV}

\section{Cambios institucionales recientes}

Para situar mejor el diagnóstico, es preciso tener presente que en la federación brasileña, como en todas las federaciones, las esferas subnacionales de gobierno se sienten menos obligadas a preocuparse de variables macroeconómicas relacionadas con la estabilidad de precios, el déficit fiscal, el comercio exterior o la balanza de pagos. ${ }^{20}$ En este sentido, el gran desafío que la federación brasileña tuvo que enfrentar después del Plan Real fue cómo conciliar la mayor o menor descentralización fiscal con los objetivos nacionales y más racionales de la política económica.

Con posterioridad al Plan Real, la estabilidad recién conquistada y la necesidad de afirmar una imagen externa positiva de la economía brasileña hizo que la política

\footnotetext{
${ }^{20}$ Véase una reflexión sobre la descentralización fiscal, la estabilidad de precios y la política macroeconómica, que incluye el caso brasileño, en Afonso (1996) y Dillinger y Webb (1999) y, en el ámbito internacional, véase Spahn (1999).
}

económica concentrara su atención en el control del déficit público y, de allí en más, sobre las relaciones federativas. Hasta mediados de los años 1990 había una gran preocupación por el papel de los estados y municipios en el descontrol del déficit fiscal, debido a su gran peso dentro del sector público, a la asimetría en la distribución de derechos y deberes entre las tres esferas de gobierno, a la existencia de bancos estaduales que financiaban los déficit y a la posibilidad de emisión de títulos de deuda en bonos, con el mismo propósito. Contribuía también a esto la influencia política directa de gobernadores y alcaldes sobre el Congreso Nacional, en un sistema electoral y partidario como el brasileño. Además, el Senado, que tiene la atribución constitucional exclusiva de limitar el endeudamiento público, en la práctica rara vez ha adoptado un comportamiento restrictivo en esta materia.

Por otra parte, a diferencia de lo que ocurre en federaciones como la estadounidense, el gobierno central de Brasil siempre actuaba (sin excepciones) como 
prestamista de última instancia para estados y municipios en quiebra, lo que alentaba a los gobiernos subnacionales a tener un comportamiento fiscal más permisivo. Las raíces de este fenómeno se remontan a la tradición del Estado centralizado, y a factores culturales y políticos, como el sistema partidario y el de representación en el Congreso.

Los intentos de perfeccionamiento del sistema federativo en los años 1990 se tradujeron en la adopción por parte del gobierno federal de una serie de medidas de conciliación, sin perder nunca de vista la antigua recomendación de Tocqueville (1957, p.156): Para unir las diversas ventajas que resultan de la grandeza y de la pequeñez de las naciones se creó el sistema federativo. Esas medidas incluyeron cambios de los esquemas de renegociación de las deudas subnacionales, la reforma del impuesto estadual sobre la circulación de mercaderías y servicios (ICMS) (en virtud de la denominada Ley Kandir) y la creación de la ley de responsabilidad fiscal, entre otras. En común, tales iniciativas constituyeron formas de enfrentar los problemas federativos más candentes, dentro de una estrategia de acción gradual y prudente, aunque costosa en términos financieros.

En cuanto a la renegociación de las deudas subnacionales, comenzando por la deuda externa vencida y no pagada desde fines de los años ochenta, pasando a la deuda interna bancaria y llegando finalmente a la deuda en bonos, tales débitos fueron consolidados y asumidos por el Tesoro Nacional mediante sucesivos programas de refinanciamiento. La última ronda de refinanciamiento de las deudas finalizó en 1999; el gobierno central asumió la deuda de los estados, que ascendía a 132.000 millones de reales (Ley 9.496/97) ${ }^{21} \mathrm{y}$, en la víspera de la publicación de la ley de responsabilidad fiscal, en mayo de 2000, se hizo cargo de las deudas de 180 municipios, por 16.400 millones de reales (medida provisoria 1.811/99). En contrapartida, los estados y municipios asumieron deudas con el Tesoro Nacional que se financiarían por 30 años como mínimo, cuyos intereses variaban del $6 \%$ al $9 \%$ al año y cuyas cuotas mensuales se restringían a un máximo de $13 \%$ del ingreso líquido. El cumplimiento se garantizó con una enmienda constitucional, que permitió al Tesoro Nacional retener y compensar los eventuales valores vencidos y no pagados de las transferencias constitucionales a las que los gobiernos subnacionales deudores tendrían derecho, así como extraer fondos directamente de la cuenta bancaria

${ }^{21}$ Véase en Mora (2002) más detalles sobre los acuerdos de refinanciamiento de la deuda estadual. centralizadora de los movimientos financieros del propio gobierno. A cambio, el gobierno federal:

i) intervino, liquidó o vendió al sector privado la mayor parte de los bancos estaduales; a partir de 1994, todos los grandes estados privatizaron, liquidaron o transfirieron sus bancos a la administración del Banco Central; ${ }^{22}$

ii) obtuvo la suspensión de la emisión de nuevas deudas en bonos estaduales o municipales, mediante restricciones contenidas en los contratos de refinanciamiento;

iii) indujo a una amplia desestatización en los gobiernos subnacionales, especialmente en las áreas de transporte y electricidad; desde 1996 hasta el 2003, se privatizaron o enajenaron participaciones en 55 empresas estaduales, alcanzando un resultado total de 34.700 millones de dólares (de los cuales 27.900 millones corresponden a la venta y 6.800 millones a la deuda transferida). ${ }^{23}$

La concepción y aprobación de la ley de responsabilidad fiscal solo fue posible al cabo de un proceso de refinanciamiento y ajuste fiscal de los principales gobiernos subnacionales. ${ }^{24}$ En definitiva, uno de los cambios estructurales más profundos que tal legislación produjo fue impedir la concesión de nuevos préstamos entre gobiernos o el refinanciamiento de deudas pasadas. Así se rompió una tradición secular de la federación brasileña. Solo el último ajuste de cuentas con el pasado pudo justificar y permitir la adopción de una nueva y radical regla, por la cual se restringió toda forma de endeudamiento entre gobiernos (incluso a los avales del Tesoro Nacional en operaciones externas se les pasó a exigir garantías reales).

El principio del gradualismo marcó la implantación de la ley de responsabilidad fiscal, sobre todo en

\footnotetext{
${ }^{22}$ De 1997 al 2005, cuando se produjo la última privatización de un banco estadual, se vendieron 12 bancos estaduales, incluidos los dos mayores: Banco do Estado de São Paulo (Banespa) y Banco do Estado do Rio de Janeiro (Banerj), operación que recaudó un total de 6.800 millones de dólares. Aún quedan bajo la administración del Banco Central los bancos estaduales de Piauí y Santa Catarina.

${ }^{23}$ Cabe mencionar que, entre 1991 y 2003, el monto total de las privatizaciones en el ámbito del gobierno federal fue de 70.800 millones de dólares, de los cuales 59.500 millones corresponden a resultados directos y 11.300 millones a deudas transferidas (véase más información en BNDES, 2004).

${ }^{24}$ Con la Ley de responsabilidad fiscal se introdujo una serie de innovaciones en la gestión pública, como la obligación de observar el equilibrio entre gastos e ingresos y de incluir un anexo de metas fiscales, además de la obligatoriedad de tener una reserva de emergencia en la ley presupuestaria. También se limitó el gasto en el sector público, se impidió el refinanciamiento de las deudas estaduales y se determinó que las operaciones de anticipación de ingresos presupuestarios pasaran a pagarse en el mismo año en que fueran efectuadas.
} 
la corrección de posibles excesos respecto a los límites. En el caso de los gastos por concepto de personal se dieron más de dos años para reducirlos al monto máximo permitido y, en el caso de la deuda consolidada, cuyo límite está fijado por el Senado Federal, se contempló un plazo de 15 años para que los gobiernos que habían refinanciado sus deudas con el Tesoro las redujeran a ese monto máximo. Además, siguiendo la práctica adoptada desde que se iniciaron las negociaciones para el refinanciamiento de las deudas, el gobierno federal ofreció líneas de financiamiento para apoyar inversiones estaduales y municipales en la modernización de la administración de los ingresos y también en la gestión fiscal.

Otro frente de modificaciones institucionales en la federación fue la descentralización de responsabilidades $\mathrm{y}$ atribuciones.

En el caso de la educación, por ejemplo, se aprobó una sistemática aplicación de recursos a través del Fondo de Mantención y Desarrollo de la Educación Fundamental y de Valorización del Magisterio (FUNDEF). ${ }^{25}$ Se trató de una medida constitucional transitoria, aprobada en 1996 y vigente hasta el 2006. El principal objetivo fue universalizar la cobertura de la educación fundamental, ${ }^{26}$ induciendo a los municipios a asumir una parte cada vez mayor de la red pública. Para ello se modificó el sistema de repartición de los recursos entre gobiernos (en proporción al número de alumnos matriculados). Los recursos pasaron a estar vinculados al FUNDEF, a partir de la tradicional asignación de impuestos a la educación. Un estímulo para la creación del fondo estuvo a cargo del gobierno central, que traspasó cerca de 500.000 millones de reales al año, a título de complementación para los estados, los que aplican un valor por alumno inferior al mínimo nacional en la enseñanza fundamental. ${ }^{27}$

\footnotetext{
${ }^{25}$ Por un plazo de 10 años, en virtud de la enmienda constitucional $\mathrm{N}^{\circ} 14$, se creó un fondo en el ámbito de cada estado, al cual se destinó el $15 \%$ del monto de las transferencias de los fondos de participación y de la respectiva recaudación del ICMS. En 2005, los recursos del FUNDEF totalizaron 32.700 millones de reales. A diferencia de los criterios normalmente aplicados según la legislación tributaria para la distribución de estos recursos entre el estado y el conjunto de sus municipios y, en el ámbito municipal, entre las alcaldías, el prorrateo de cada fondo estadual es proporcional al número de alumnos matriculados en la respectiva red de educación fundamental a fin de promover una mejor distribución de la capacidad de gasto. En la práctica, en el caso de los gobiernos que recaudaban mucho y gastaban poco por alumno, parte de sus ingresos se redistribuyeron a otros gobiernos.

${ }^{26}$ En Brasil se entiende por educación fundamental la que se imparte a niños desde los 7 años hasta los 14 años.

${ }^{27}$ Además, los estados que sufrieron pérdidas más cuantiosas con la "municipalización" de los ingresos vinculados promovida por el FUNDEF fueron compensados con préstamos extraordinarios concedidos por el Tesoro Nacional.
}

En el sector de la salud el gobierno federal inicialmente intentó estimular el fortalecimiento de programas de atención primaria (como los relativos a deficiencias nutricionales y a farmacia básica), dejando la ejecución en manos de las autoridades estaduales y, sobre todo, municipales. Se creó un fondo para financiar las medidas básicas de los municipios, que efectuaba transferencias directas según criterios per cápita a través del Piso de Atención Básica (PAB); del mismo modo, se subsidió la formación de equipos de salud familiar y se entregó la gestión plena de los recursos y de su asignación, desde la atención primaria hasta la terciaria, a los municipios capacitados en salud pública. Las transferencias en el ámbito de los programas de atención básica de salud costaron cerca de 6.000 millones de reales en 2005 y solo al PAB se destinaron 2.300 millones de reales. ${ }^{28}$ En una segunda instancia, el cambio institucional más relevante requirió una reforma constitucional (enmienda $\mathrm{N}^{\circ} 29$, de septiembre del 2000) con vistas a exigir un monto mínimo de aplicaciones de recursos tributarios en el Sistema Único de Salud (SUS) por el gobierno central y los gobiernos estaduales y municipales. Contrariamente a lo ocurrido en el sector de la educación, en que la asignación se establece en el cuerpo mismo de la Constitución, en este caso se remitió el asunto a una ley complementaria. Hasta la publicación de esta ley (la que no se ha concretado hasta hoy), la norma transitoria de la misma enmienda constitucional exige que el gobierno central corrija año a año sus gastos relativos al SUS de acuerdo con la variación nominal del PIB y que los estados y municipios destinen al sistema, como mínimo, un $12 \%$ y $15 \%$ respectivamente del ingreso derivado de los impuestos.

En cuanto al tema de la tributación el enfoque de Brasil está íntimamente ligado a la cuestión federativa. Es tradición secular brasileña establecer en la Constitución competencias tributarias exclusivas por esfera de gobierno y disponer sobre la materia con gran detalle. Se define así el llamado pacto federativo, sin mayor preocupación por los efectos sobre la magnitud y la división del gasto, resultantes del patrón de financiamiento predefinido.

En el primer proyecto de reforma importante propuesto por el gobierno federal en 1995 se rechazaba explícitamente la idea de promover una recentralización de los ingresos. El objetivo fundamental era unificar la

\footnotetext{
${ }^{28} \mathrm{El}$ impacto de esta medida fue aún mayor en el ámbito municipal. Con la transferencia garantizada del mínimo (PAB-fijo) de 10 reales por habitante al año para todas las alcaldías del país, muchas pasaron a recibir del gobierno federal entre dos y nueve veces más que lo que recibían anteriormente por el sistema normal del Sistema Único de Salud (SUS), que era la facturación de servicios prestados.
} 
legislación nacional del impuesto sobre el valor agregado, detener la guerra fiscal y crear un impuesto federal idéntico al estadual (misma base, factor generador y legislación), así como unificar las actuales contribuciones a la seguridad social y sustituir su base de incidencia sobre la facturación total de las ventas por el valor agregado, también con miras a eliminar sus efectos adversos sobre la competitividad de la economía. En la perspectiva de un modelo de impuesto al valor agregado (IVA), con cobro compartido entre el gobierno federal y los gobiernos estaduales, se preveía la aplicación simultánea de dos alícuotas, lo que permitiría implantar el principio de destino en las transacciones interestaduales. Esto evitaría la evasión derivada de una mera eliminación de la alícuota en las salidas de mercaderías a otros estados y, además, pondría fin a la encarnizada guerra fiscal entre los estados brasileños. ${ }^{29}$ Sin embargo, la premura por generar un ajuste fiscal para hacer frente a la grave crisis externa llevó al gobierno federal a retroceder en su iniciativa de reforma en el Congreso.

La nueva administración federal envió en el 2003 un proyecto de reforma que, en esencia, perseguía los mismos objetivos de largo plazo. Una vez más, no se aprobaron los cambios, dado que las autoridades económicas concentraron los esfuerzos en las medidas de corto plazo, como la prórroga de la contribución provisoria sobre los movimientos financieros (CPMF) y la desvinculación de los ingresos federales.

No obstante, hubo cambios relevantes en la legislación infraconstitucional después de la implantación del real. Tras modificaciones importantes, como el fin de la corrección monetaria del balance de las empresas y la creación de un sistema simplificado de tributación federal para microempresas y pequeñas empresas, el gobierno federal apoyó los cambios en el impuesto estadual sobre la circulación de mercaderías y servicios promovidos por la llamada Ley Kandir y, posteriormente, en las contribuciones sociales sobre las ventas (las destinadas al Programa de Integración Social (PIS) y luego al financiamiento de la seguridad social (COFINS)).

Para el enfoque federativo la medida de impacto más directo fue la Ley Kandir, una ley complementaria de septiembre de 1996 ( $\mathrm{N}^{\circ}$ 87), por la que se eliminó la aplicación directa del impuesto estadual sobre la circulación de mercaderías y servicios a todas las exportaciones,

\footnotetext{
${ }^{29}$ Esta idea está en línea con los ideales del "IVA dual", defendido por Bird y Gendron (1997). El sistema detallado del proyecto del ICMS compartido, objeto de debate en Brasil y Argentina (también conocido como little boat model debido al trato que se da a las transacciones interestaduales), figura en Varsano (2000) y ha sido comentado y defendido por McLure (1999) y Bird (2000).
}

inclusive de productos primarios y semielaborados. La tributación para los que imponían los estados sobre las ventas al exterior era una tradición de siglos en el país y se remontaba a las capitanías hereditarias. Los estados solo aceptaron renunciar a la facultad de gravar las exportaciones a cambio de apoyo financiero del gobierno federal, acordado en ese entonces como un sistema transitorio (hasta un máximo de 12 años) en la forma de un "segurorecaudación" (se traspasarían recursos solo a los estados que hubieran sufrido una merma de la recaudación y en monto proporcional a tal pérdida); con posterioridad, esto se convirtió en una transferencia federal (de cerca de 4.000 millones de reales al año), con un prorrateo prefijado, que tendría carácter compensatorio.

La Ley Kandir acabó originando dos focos permanentes de conflictos que contaminaron las relaciones federativas y la competitividad de la economía. Por un lado, año tras año la negociación de los traspasos quedaba pendiente, dado que para su aprobación en el presupuesto federal faltaban principios claros que orientaran la definición del monto global de las transferencias y también criterios adecuados para distribuir los recursos entre los estados que más los necesitaban. ${ }^{30}$ Por otra parte, el hecho de que la exoneración no fuera automática (sin transferencia a terceros o resarcimiento en especie) hizo que, dependiendo de las autoridades estaduales, los exportadores pudieran acumular voluminosos saldos acreedores del impuesto estadual sobre la circulación de mercaderías y servicios, contrariando el espíritu de la propia ley e incluso de la Constitución (luego de que mediante una reforma parcial en el 2003 se traspasara el precepto antes enunciado en la Ley Kandir a la Carta Magna). Más aún, se difundió entre los gobiernos estaduales la idea de que exportar era perjudicial, ya que no generaba ingresos y además suponía gastos. Algunos gobernadores no solo demoraban o rechazaban la devolución de créditos, sino que también se resistían a veces a conceder incentivos y apoyo de infraestructura a nuevos proyectos que se orientaran principalmente al mercado externo.

Cabe mencionar además, en el campo tributario, que el arreglo federativo de 1988 fue modificado por un movimiento recurrente de todos los gobiernos federales del período posterior a la Asamblea Nacional Constituyente, que apuntaba a elevar las contribuciones a la seguridad social y otros gravámenes que no significaran compartir ingresos con estados y municipios. Esto se debió a que se exageró en la distribución constitucional de lo recaudado

\footnotetext{
${ }^{30}$ Originalmente la Ley Kandir contemplaba en su anexo un detallado e innovador esquema de transferencia, el "seguro-recaudación", que finalmente se anuló a petición de los estados.
} 
por los impuestos. El gobierno central procuró explotar las mismas bases tributarias mediante contribuciones que no son compartidas y que además están sujetas a menos restricciones a la facultad de establecer tributos (como es el caso del principio de anualidad, que no afecta a las contribuciones a la seguridad social).

La circunstancia de que aproximadamente la mitad de los ingresos provenientes de los dos principales impuestos federales (impuesto sobre la renta e impuesto sobre los productos industrializados) se transfiera a los otros gobiernos indujo al gobierno central a crear una contribución social sobre el lucro de las empresas (con una alícuota menor, pero con una base más amplia que la del impuesto sobre la renta de los mismos contribuyentes). Además, mantuvo y elevó, continua y significativamente, las contribuciones sobre la facturación y los demás ingresos, que antes de la Asamblea Nacional Constituyente se aplicaban a través de un fondo federal, el Fondo de Inversión Social (FINSOCIAL). Posteriormente, un impuesto sobre los movimientos financieros que estuvo en vigor solo el año 1994, fue reimplantado bajo el nombre de contribución provisoria sobre el movimiento financiero (CPMF). Estas contribuciones sociales, por ser acumulativas, tuvieron por lo general efectos negativos sobre la competitividad de la economía. El reciente intento (2002-2003) de atenuar la acumulación de las contribuciones al Programa de Integración Social (PIS) y a la contribución para el financiamiento de la seguridad social (COFINS) acabó ampliando la carga tributaria debido a la calibración equivocada de la nueva alícuota, ya sea por el cambio de régimen o por la ampliación de la base para gravar importaciones sin reducir la tributación en el mercado local.

La evolución histórica de la estructura de la carga tributaria brasileña muestra, por una parte, una drástica disminución de la carga correspondiente al único impuesto federal que se asemeja al de valor agregado: el impuesto sobre los productos industrializados (IPI). En 1970 se recaudó el equivalente al 4,4\% del PIB; en 1980 y 1990, ese porcentaje bajó a la mitad; 10 años más tarde (en el 2000) no pasó del 1,6\% del PIB y en el 2005 quedó en $1,2 \%$, uno de los niveles más bajos de su historia. En cambio, las contribuciones sociales que tienen incidencia sobre el ingreso en general y la facturación - como el Programa de Integración Social (PIS) o el Plan de Asistencia al Funcionario Público (PASEP), creado a inicios de los años 1970, y también la contribución para el financiamiento de la seguridad social (COFINS), establecido a comienzos de los años 1980 con el nombre de Fondo para la Inversión Social (FINSOCIAL) - se ampliaron vigorosamente tras la reforma de 1988. En
1980, la recaudación del PIS ascendió a apenas un 1\% del PIB; en 1990, ambas contribuciones (PIS y COFINS) recaudaron el 2,7\% del producto; en el 2000, la carga conjunta fue del 4,4\% del PIB, y en el 2005 alcanzó la cifra récord de 5,6\% (de la cual 4,4 puntos porcentuales correspondían a la COFINS). Incluida la recaudación de 1,5\% del PIB obtenida con la CPMF y de 1,3 puntos con la contribución social sobre las utilidades netas (CSLL), ${ }^{31}$ la carga tributaria derivada de las cuatro contribuciones (PIS, COFINS, CSLL y CPMF) llegó al 8,4\% del PIB en el 2005. Ese monto equivale a más de seis veces la recaudación del impuesto federal sobre los productos industrializados y supera la recaudación del impuesto estadual sobre la circulación de mercaderías y servicios o la del impuesto federal sobre la renta.

La extraordinaria transformación señalada sugiere que el proceso de cambios graduales y flexibilidad razonable en las relaciones federativas fue abandonado, intencionalmente o no. Las políticas públicas, macroeconómicas y sociales revelan forzosamente una recentralización fiscal, incluso para atender a la presión creciente de los enormes gastos en transferencia de ingresos, que van desde los beneficios sociales hasta los intereses de la deuda pública.

Esa realidad de la recentralización también se refleja en el control del endeudamiento público estadual y municipal. Pese a la generación de crecientes superávit primarios, la reducción y casi anulación del endeudamiento bancario subnacional y, lo que es más importante, el pago de todas las prestaciones mensuales vencidas, al final de abril de 2006 la deuda neta de estados y municipios y sus respectivas deudas con el gobierno central acumulaban un total equivalente al $19,1 \%$ del PIB, de acuerdo con el Banco Central. De ese total, más del $95 \%$ correspondía a contratos de refinanciamiento con el Tesoro Nacional.

El mantenimiento de un acervo de deuda tan elevado - por no decir creciente en los últimos años, según el año que se tome como base para la evaluación- deriva de un problema que no fue previsto al diseñar los programas de refinanciamiento: el régimen cambiario vigente inmediatamente después de la adopción del real era fijo o semifijo y no había duda sobre la adopción del Índice General de PreciosDisponibilidades Internas (IGP-DI) como indicador del refinanciamiento. Sin embargo, cuando se estableció el tipo de cambio fluctuante, el IGP pasó a oscilar sensiblemente y acumuló una variación muy superior

\footnotetext{
${ }^{31}$ Contribução social sobre o lucro líquido (CSLL).
} 
al índice oficial adoptado en el régimen de metas de inflación —el índice nacional de precios al consumidor en su concepto amplio (IPCA) - entre el año 2000 y el 2004. A partir de este último año, con el nuevo ciclo de sobrevalorización del real, el problema disminuyó, pero parece inevitable que reaparezca cuando el tipo de cambio vuelva a sus niveles habituales.

De todos modos, se perdió el equilibrio del contrato de refinanciamiento, sobre todo porque, además de la indización inflada, los saldos también están sujetos a tasas de interés reales que anualmente han triplicado, o más, la tasa media de crecimiento real de la economía. En consecuencia, a pesar de que entre el 2001 y el 2005 los gobiernos estaduales y municipales pagaron al Tesoro Nacional un monto acumulado de 70.100 millones de reales solo por concepto de las tres principales operaciones de refinanciamiento (leyes 9.496/97 y $8.727 / 93$ y medida provisoria 2.185 ), al 31 de diciembre de 2005 debían un saldo absurdo de 336.800 millones de reales, es decir, 137.500 millones de reales más que cinco años antes.

Como el servicio mensual de la deuda estadual y municipal por vencer se calcula por el máximo fijado en proporción de los ingresos corrientes (la mayoría de las veces), el desequilibrio en el mecanismo de valoración de las deudas produce un efecto artificial de orden patrimonial y contable, más que un impacto financiero inmediato. Esto compromete la transparencia y la gestión de la política fiscal y macroeconómica, fenómeno que pasa inadvertido para los que desconocen los detalles y sutilezas de la liquidación de la deuda neta y de los resultados primario y nominal. Como no afecta los flujos, sino que altera los acervos, no provoca protestas más vehementes de las autoridades estaduales y municipales. Las autoridades económicas federales aprovechan la "supercorrección" de los créditos a los estados y municipios para disimular una expansión más acelerada de las deudas federales, especialmente la deuda en bonos. En este caso, sin efectos artificiales, pues resulta de la aplicación de tasas de interés reales absurdamente elevadas, especialmente para los parámetros internacionales.

Cabe citar como ejemplo la evolución reciente de los resultados fiscales, recordando que el concepto más relevante es el de déficit nominal, ya que sirvió de poco la elevación del superávit primario federal cuando los gastos por intereses en esa esfera crecieron por un monto superior. Entre los períodos 2000-2002 y 2003-2005, el superávit primario del gobierno central aumentó de $2 \%$ a $2,8 \%$ del PIB, pero el gasto en intereses nominales pasó del $3,7 \%$ al $5,9 \%$. Por eso, casi se duplicó el déficit nominal de esa esfera de gobierno, del 1,7\% al 3,1\% del PIB, entre ambos trienios. ${ }^{32}$ Sin embargo, cuando se toma al sector público como un todo, hay una pequeña reducción del déficit nominal (del 3,9\% al 3,7\% del PIB entre los dos períodos analizados), lo que se explica por la sensible mejora de los resultados de las empresas estatales y, sobre todo, de los gobiernos estaduales y municipales (el déficit subnacional bajó del 3,1\% a menos del 0,3\% del PIB, entre 1999 y el 2005, y tiende a ubicarse en cero en el 2006). O sea, el déficit nominal del gobierno central creció y el de los gobiernos subnacionales bajó, lo que refuerza la sensación de que la ley de responsabilidad fiscal se hizo con el solo propósito de llamar al orden a los estados y municipios.

Los desarreglos federativos también han aumentado en lo que se refiere a la división de responsabilidades y competencias. En el campo de las políticas públicas sociales, las autoridades federales privilegiaron la expansión de programas de beneficios focalizados, en detrimento de los gastos de carácter universal, como aquellos en educación fundamental y en atención de la salud. Está en curso una expansión acelerada de gastos en previsión y asistencia social. Además de los efectos de la corrección del salario mínimo, el número de los nuevos beneficios sociales (concedidos a jubilados y beneficiarios de los sistemas públicos de seguro social) aumentó muy por encima de cualquier medida de expansión demográfica, especialmente en los casos de subsidios por enfermedad y beneficios asistenciales de renta continuada, incluida la fusión en el programa Bolsa-Familia de la asistencia financiera concedida antes a las familias en el marco de los programas Bolsa-Escola, Bolsa-Alimentação, erradicación de trabajo infantil y Vale-Gas. Tal orientación en sí no traería mayores problemas si, en un primer momento, no hubiera exigido una nueva ronda de aumentos de la carga tributaria, sobre todo mediante cambios en la COFINS. En segundo lugar, se profundizó el dilema presupuestario, ya que los gastos de mantenimiento

\footnotetext{
32 Dicho de otra manera, el gobierno central, responsable de solo el $44 \%$ del déficit nominal del sector público entre los años 2000 y 2002, pasó a generar el 84\% del déficit en los últimos tres años. Esto se debe básicamente a la participación federal en el gasto en intereses de la deuda pública, que subió del $49 \%$ al 71\%. La variable intereses es fundamental para explicar tal evolución. Dichos gastos del gobierno central bajaron 1,9 puntos del PIB entre 2000 y 2002, aunque crecieron 3,56 puntos del PIB entre 2002 y 2005. En suma, el papel del gobierno central ha cambiado. Entre el 2000 y el 2002 fue el principal responsable de la reducción del déficit nominal como proporción del PIB (aunque el déficit nominal de los gobiernos subnacionales aumentó), pero en los últimos tres años esta tendencia se invirtió.
} 
aumentaron a tasas crecientes y superaron la expansión de los ingresos, reduciendo aún más el espacio para las inversiones productivas, especialmente en infraestructura.

La tendencia del gobierno federal a asistir y beneficiar directamente a la población tiene repercusiones importantes en las relaciones federativas. En primer lugar porque la asistencia era antes un gasto típicamente local y pasó a ser financiada cada vez más por el presupuesto federal. Aunque las alcaldías actúen como socias (para hacer un catastro y un seguimiento de las familias atendidas), obviamente no lo hacen con el mismo ahínco o eficacia que cuando gastaban sus propios recursos. Pero el problema mayor ha sido la falta de prioridad de los programas sociales de carácter universal, en los cuales los gobiernos estaduales y municipales tienen un papel decisivo en la ejecución del gasto, en especial en el caso de la educación y de la salud. Los aportes federales para tales programas no han aumentado e incluso se han reducido (salud). Aún corren serios riesgos en el cortísimo plazo: el FUNDEF terminará al final del 2006 y todavía no se ha aprobado en el Congreso la propuesta de crear otro fondo, el fondo de desarrollo de la enseñanza básica (FUNDEB). Con este nuevo fondo se promete aumentar el traspaso de recursos federales al establecer en la Constitución el monto nominal de las transferencias, pero sin indicar la fuente de esos recursos. Es decir, se está trazando el mismo camino del conflicto de intereses que ya marcó la Ley Kandir. En materia de salud, las autoridades federales han intentado soslayar la aplicación obligatoria definida por una enmienda constitucional del año 2000 incluyendo contablemente gastos que no son de Salud, como es el caso de beneficios pagos por el programa de Bolsa-Familia, mientras que se ha venido obligando cada vez más a estados y municipios a financiar los gastos de esa área con recursos propios.

En el campo tributario propiamente dicho el síntoma básico del desarreglo federativo ya se mencionó: las medidas tributarias recientes llevaron al extremo la opción de aumentar las contribuciones no compartidas y concentrar la concesión de beneficios en los impuestos repartidos con estados y municipios.

Entre el 2002 y el 2005, la carga tributaria global aumentó 2,3 puntos del PIB. El impuesto estadual sobre la circulación de mercaderías y servicios originó el $12 \%$ de ese aumento y el peso de la COFINS/PIS fue tres veces mayor. Si bien el aumento de la recaudación tributaria atenúa los efectos sobre los presupuestos, la división federativa del ingreso disponible (una vez computadas las transferencias constitucionales) señalan el fuerte aumento de la participación federal, que en los últimos cinco años creció 1,8 puntos porcentuales, al pasar del $55,8 \%$ al $57,6 \%$ del total de la recaudación tributaria nacional. Cuando se toma 1991 como base (el año de menor participación federal después de la Asamblea Nacional Constituyente) se comprueba que la participación federal total aumentó 2,9 puntos porcentuales y la municipal 1,5 puntos, mientras la estadual retrocedió 4,4 puntos porcentuales (véase el cuadro 1 y el gráfico 1 anteriores).

En una perspectiva de más largo plazo, al cabo de cuatro décadas los municipios han asumido la posición que era de los estados como polo dinámico del federalismo brasileño, a juzgar por la evolución de la división federativa del ingreso tributario disponible. Los gobiernos estaduales perdieron 10 puntos porcentuales de participación; en 1965, antes de la reforma promovida por los gobiernos militares, percibían el $35 \%$ de la carga tributaria global; cuatro décadas después la cifra bajó a aproximadamente un $25 \%$. En ese largo período la participación de los gobiernos municipales aumentó de un $10 \%$ a un $17 \%$ del ingreso global.

Como era de esperar, los gobernadores detectaron el problema, pero optaron por apoyar soluciones que finalmente resultaron ineficaces. Así, en la enmienda constitucional promulgada a fines de 2003, los gobiernos subnacionales lograron que se les traspasara la cuarta parte de lo recaudado a través de la contribución de intervención en el dominio económico (CIDE), aunque vinculada a inversiones en transportes, dado que el gobierno federal había creado este gravamen y lo estaba utilizando en gran escala. La recaudación de la contribución mencionada exhibió enseguida uno de los peores desempeños entre los ingresos federales (posiblemente parte de su incidencia se trasladó a la COFINS, que se mantiene en un $100 \%$ en los cofres de la Unión). En cuanto al proyecto que todavía se tramita de la misma reforma, los defensores del municipalismo optaron por exigir que aumentara en un punto la porción del impuesto sobre la renta y sobre los productos industrializados que se destinaba al Fondo de Participación de los Municipios y que debía entregarse el último mes del año; no obstante, hasta ahora, el proyecto no fue votado, obstruido por el gobierno federal. Este, por ejemplo, cuando publicó una medida provisoria en 2005 que exoneraba a las inversiones, concedía la mayoría de los incentivos en el ámbito del impuesto sobre la renta de las personas jurídicas (IRPJ), que no es compartido. Los desencuentros determinaron también el retraso e incluso los recortes de los traspasos en virtud de la Ley Kandir, como ya se indicó. 
En suma, el principal objetivo de los constituyentes de 1988 de promover una descentralización fiscal desembocó en definitiva en una tendencia inequívoca a la municipali- zación y, en el período más reciente, en una recuperación de la importancia relativa del gobierno federal, siendo los estados los grandes "perjudicados" en esta historia.

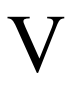

\section{Por una nueva agenda federativa}

La federación fiscal brasileña es una buena proyección del cuadro general de su economía, de su sociedad y de su sistema político. Por una parte, ostenta elevados índices de participación de los gobiernos subnacionales en la generación directa e incluso en la asignación de los ingresos tributarios, así como en la realización de los gastos de personal, bienes y servicios, además de administrar sus presupuestos con una interferencia mínima del gobierno central. Por otra parte, no existe un proceso planificado y organizado de descentralización fiscal que permita conciliar la redistribución de ingresos y la división de cargas. Esto contribuye a acentuar la complejidad de las relaciones federativas, además de conspirar contra su eficiencia económica y contra la calidad de los servicios públicos. Asimismo, la diferencia de la carga tributaria entre los estados más y menos desarrollados de la federación es enorme.

Hay una extensa agenda de cuestiones que deberá enfrentar la federación brasileña en los próximos años. Si bien ya existían problemas antiguos, llamados estructurales, cuyas soluciones permanecían pendientes, en los últimos años surgieron nuevos desafíos, entre los cuales está la gradual recentralización. Esto fue más evidente en el caso del ejercicio de las competencias tributarias, con hechos que contaminaron progresivamente las transferencias federales (menoscabando las bases de los fondos de participación y reduciendo los traspasos vinculados a la Ley Kandir). También afectó la ejecución de los gastos, dejando en segundo plano algunos programas de medidas estructurales conjuntas con los gobiernos locales (como en la atención de la salud), a cambio de privilegiar medidas directas (como la farmacia popular y la asistencia hospitalaria). Debido a las distorsiones estructurales y a los nuevos problemas fiscales, aumentaron los conflictos dentro de la federación.

Es preciso tener presente, sin embargo, que una eventual recentralización del poder en manos del gobierno federal, que inaugurara una nueva fase cíclica en el recorrido histórico de la federación brasileña, no encontró amparo en la agenda del gobierno federal: sería inviable desde el punto de vista político e incluso indeseable desde el punto de vista de la eficiencia administrativa y del bienestar social en un país heterogéneo y de dimensiones físicas y demográficas tan grandes. Un razonamiento similar, con mayor énfasis en las condiciones políticas, evitaría también la inclusión en esa agenda de intentos de cambiar la distribución regional de los recursos públicos federales de origen fiscal.

Donde poco o nada se ha avanzado ha sido en la reducción de la llamada guerra fiscal entre los estados, mediante la manipulación del respectivo impuesto sobre la circulación de mercaderías y servicios y la concesión de beneficios (en especial, la devolución de la porción de impuesto que le correspondería a los demás estados) bajo el disfraz de préstamos subsidiados e incluso participaciones accionarias. El efecto principal de esa manipulación era y es reducir el ingreso estadual efectivamente disponible, como un todo, y aumentar las presiones fiscales de los gobiernos estaduales sobre el gobierno central. Esto sin contar el hecho de que la disputa sin reglas respecto del impuesto sobre la circulación de mercaderías y servicios fue por cierto uno de los factores determinantes en la reversión de la tendencia histórica hacia la desconcentración regional de la economía. El caso reciente de las plantas de ensamblaje de automóviles es emblemático: una vez declarada la concesión generalizada de incentivos, los estados más desarrollados acaban por aprovecharse de las ventajas obvias como, por ejemplo, su localización del mercado y su mejor infraestructura económica y social. ${ }^{33}$

\footnotetext{
${ }^{33}$ Un síntoma del freno de la tendencia histórica y natural hacia la desconcentración económica está dado por la comparación entre las tasas de crecimiento real del PIB en el período posterior a la instauración del real (en que se intensificó la guerra fiscal). Entre 1994 y el 2005, el PIB nacional acumuló una expansión del 29,7\% y el PIB paulista una del 31,5\% (según datos del IBGE y de la Fundación Sistema Estadual de Análisis de Datos (SEADE), respectivamente). La economía de ese estado logró crecer mucho más rápido que la nacional en las fases de aceleración (como en el 2004 y el 2005) y así compensar con creces la situación inversa, de caer más que la tasa nacional en las fases de desaceleración de los cortos ciclos económicos.
} 
Las consecuencias de la guerra del impuesto sobre la circulación de mercaderías y servicios van más allá de la dimensión fiscal, pues están muy relacionadas con el rumbo de las políticas industriales y de comercio exterior. ${ }^{34}$ Estas, a su vez, son indispensables para la firme reactivación del crecimiento económico. A este respecto, cabe señalar que la apertura económica y financiera de la economía brasileña en los años 1990, después de por lo menos seis décadas de crecimiento económico hacia adentro (proteccionismo y fuerte intervención estatal), de hecho ha complicado las relaciones federativas. En una economía más abierta, es menor la solidaridad y son mayores las diferencias de intereses y visiones entre las regiones más y menos desarrolladas en términos de política comercial e industrial. ${ }^{35}$

Otra área importante donde no hubo iniciativa alguna es la esfera política de las relaciones federativas. El gobierno anterior y el actual se abstuvieron de presentar tanto propuestas de reformas al sistema electoral y partidario - con el objeto de facilitar la formación de mayorías y debilitar los lazos de dependencia de los parlamentarios con los gobernadores- como propuestas de corrección de los desequilibrios en la representación de los estados en la Cámara de Diputados. Tal omisión se debió al temor de perturbar el funcionamiento de la mayoría gubernamental en el Congreso en una época de sucesivas votaciones de enmiendas constitucionales relacionadas con la economía. Sin embargo, no hay duda de que aquellas reformas, tarde o temprano, deberán incorporarse en la agenda nacional.

Como observación final, cabe señalar que hasta el momento, a diferencia de lo que sucede en otros países, la federación brasileña, aunque esté inconclusa, da indicios de una razonable estabilidad. A ello contribuyeron la herencia del Estado unitario y la moderación de las diferencias étnicas, lingüísticas y religiosas entre los brasileños. Del mismo modo, los ciclos de contracción y expansión del poder central y la tradición conciliadora de la política brasileña han ido facilitando los ajustes necesarios a lo largo del tiempo. Específicamente, en el caso de los sistemas tributario y fiscal, los mecanismos redistributivos se utilizan para conciliar intereses regionales divergentes y contradictorios, mediante la transferencia de recursos públicos entre las diferentes esferas de gobierno y las regiones más y menos desarrolladas, con una intensidad y rapidez que pocas federaciones han logrado sin sobresaltos políticos y civiles dramáticos. No es casualidad que los ideales del federalismo fiscal se evoquen siempre en la defensa de intereses localizados y de políticas públicas de impacto regional.

La flexibilidad del federalismo brasileño, a pesar de este cuadro, deberá enfrentar exigentes pruebas en el futuro próximo, frente a los desafíos de la política de desarrollo y de la reforma política. Por lo tanto, es imperativo anticiparse a los acontecimientos, para consolidar en Brasil una federación fuerte, unida y democrática.

\section{Bibliografia}

Affonso, R. (1994): A crise da federação no Brasil, Ensaios FEE, vol. 15, $\mathrm{N}^{\circ}$ 2, Porto Alegre, Fundação de Economia e Estatística.

Affonso, R. y P. Silva (orgs.) (1995): Desigualdades regionais $e$ desenvolvimento, São Paulo, Fundación de Desarrollo Administrativo (FUNDAP).

Afonso, J. (1994): Descentralização fiscal na América Latina: estudo do caso do Brasil, serie Política fiscal, $N^{\circ}$ 61, LC/L.841, Santiago de Chile, Comisión Económica para América Latina y el Caribe (CEPAL).

(1996): Descentralizar e depois estabilizar: a complexa experiência brasileira, Revista do BNDES, vol. $3, \mathrm{~N}^{\circ} 5$, Rio de Janeiro, Banco Nacional de Desarrollo Económico y Social (BNDES), junio.

\footnotetext{
${ }^{34}$ Incluso se ha observado un fuerte movimiento de parlamentarios y gobernadores de regiones menos desarrolladas en favor de ampliar los incentivos federales para acercarlos a los estándares de la Zona Franca existente en la Amazonia. Esta Zona Franca, a diferencia de las demás que hay en el mundo, actúa esencialmente en el ámbito de las importaciones y ventas en el mercado interno.

${ }^{35}$ Véase en Affonso y Silva (1995) un análisis detallado, a partir de la óptica regional, de las perspectivas y desencuentros del federalismo en Brasil.
}

Afonso, J. y B. Meirelles (2006): Carga tributária global no Brasil, 2000/2005: cálculos revisitados, Caderno de pesquisa, No 61 , Núcleo de Estudos em Políticas Públicas/Universidad Estadual de Campinas (NEPP/ UNICAMP), marzo.

Afonso, J., E. Araújo y G. Biasoto (2005): Fiscal Space and Public Sector Investments in Infrastructure: A Brazilian Case-Study, Texto para discussão, № 1141, Brasília, Instituto de Investigación Económica Aplicada (IPEA), diciembre.

Bird, R. (2000): Subnational revenues, en S. Burki, G. Perry y otros (comps.), Annual World Bank Conference on Development in Latin America and the Caribbean: Decentralization and Accountability of the Public Sector, Washington, D.C., Banco Mundial, junio.

Bird, R. y P. Gendron (1997): Dual vaTs and cross-border trade: two problems, one solution?, Toronto, Toronto International Centre for Tax Studies, octubre, inédito.

BNDES (Banco Nacional de Desarrollo Económico y Social) (2004): Programa Nacional de Desestatização. Relatório de Atividades 2003, Rio de Janeiro.

Dillinger, W. y S. Webb (1999): Fiscal Management in Federal Democracies: Argentina and Brazil, Policy Research Working Paper, $\mathrm{N}^{\mathrm{o}}$ 2121, Washington, D.C., Banco Mundial, mayo.

Goldsmith, R. (1986): Brasil 1850-1984: desenvolvimento financeiro sob um século de inflação, São Paulo, Harper \& Row do Brasil. 
IBGE (Instituto Brasileño de Geografia y Estadística) (1999): Contas nacionais, Rio de Janeiro. (2003): Contas nacionais, Rio de Janeiro. (varios años): Contas nacionais, Rio de Janeiro.

IEDI (Instituto de Estudios para el Desarrollo Industrial) (2006): O custo político dos municípios: diagnósticos e propostas, São Paulo, enero, inédito.

McLure Jr., Ch.E. (1999): Protecting dual vaTs from evasion on crossborder trade: an addendum to Bird and Gendron, Stanford, Hoover Institution, inédito.

Mora, M. (2002): Federalismo e dívida estadual no Brasil, Texto para discussão, $\mathrm{N}^{\mathrm{o}} 866$, Rio de Janeiro, Instituto de Investigación Económica Aplicada (IPEA).

MPAS (Ministerio de Previsión y Asistencia Social) (varios años): Anuário estatístico da previdência social, Brasilia. Brasilia. (varios años): Boletim estatístico da previdência social,

Oates, W. (1999): An essay on fiscal federalism, Journal of Economic Literature, vol. 37, $\mathrm{N}^{\circ} 3$, Nashville, Tennessee, American Economic Association, septiembre.

PNUD (Programa de las Naciones Unidas para el Desarrollo) (2005): Informe sobre desarrollo humano, 2005, Madrid, Ediciones Mundi-Prensa.

Serra, J. (1997): Reforma política no Brasil, Brasilia, Senado de la República.
Serra, J. y J. Afonso (1991): Finanças públicas municipais: trajetórias e mitos, Conjuntura econômica, $\mathrm{N}^{\mathrm{o}} 10 / 11$, Rio de Janeiro, Fundación Getulio Vargas, octubre-noviembre.

Shah, A. (1994): The Reform of Intergovernmental Fiscal Relations in Developing and Emerging Market Economies, Policy and Research Series, $\mathrm{N}^{\mathrm{o}}$ 23, Washington, D.C., Banco Mundial, junio.

Spahn, P.B. (1999): Intergovernmental relations, macroeconomic stability and economic growth, Frankfurt, Goethe-University, abril, inédito.

Stepan, A. (1997): Toward a new comparative analysis of democracy and federalism: demos constraining and demos enabling federations, documento presentado en la Reunión de la Asociación Internacional de Ciencias Políticas (Seúl, agosto de 1997), inédito.

STN (Secretaría del Tesoro Nacional) (varios años): Balanço Geral da União e Finanças do Brasil, Brasilia.

Tocqueville, A. (1957): La democracia en América, México, D.F., Fondo de Cultura Económica.

Varsano, R. (2000): Subnational taxation and treatment of interstate trade in Brazil: problems and a proposed solution, en S. Burki, G. Perry y otros (comps.), Annual World Bank Conference on Development in Latin America and the Caribbean: Decentralization and Accountability of the Public Sector, Washington, D.C., Banco Mundial, junio. 